\title{
FIRM DYNAMICS WITH FRICTIONAL PRODUCT AND LABOR MARKETS*
}

\author{
By Leo KaAs and Bihemo Kimasa
}

\author{
Goethe University Frankfurt, Germany ; University of Konstanz, Germany
}

\begin{abstract}
We analyze the joint dynamics of prices, productivity, and employment across firms, building a dynamic equilibrium model of heterogeneous firms who compete for workers and customers in frictional labor and product markets. Using panel data on prices and output for German manufacturing firms, the model is calibrated to evaluate the quantitative contributions of productivity and demand for the labor market. Product market frictions decisively dampen the firms' employment adjustments to productivity shocks. We further analyze the impact of aggregate shocks to the first and second moments of productivity and demand and relate them to business-cycle features in our data.
\end{abstract}

\section{INTRODUCTION}

Firm heterogeneity matters for the labor market and for business-cycle dynamics. For instance, firms which differ in size, age, or productivity create and destroy jobs at different rates and they respond to aggregate shocks in different ways, see, for example, Davis et al. (2006), Haltiwanger et al. (2013), and Moscarini and Postel-Vinay (2012). This motivates a large literature on the role of firms in macroeconomics, much of which builds on the seminal contributions of Hopenhayn (1992) and Hopenhayn and Rogerson (1993), sometimes augmented by richer labor market features. ${ }^{1}$ In such models of firm dynamics, firms are hit by idiosyncratic transitory shocks to their revenue productivity which induces them to create or destroy jobs as they grow or contract over time. These shocks may reflect the price or the quantity components of revenue and hence could be induced by supply-side or demand-side disturbances. This seems a reasonable theoretical shortcut, given that most data sets have no separate information on firm-level prices and output. Yet one might expect that supply and demand affect the dynamics of firms in different ways and hence have distinct implications both for the cross section as well as for aggregate dynamics.

Recent empirical findings highlight a prominent role of firm-specific demand for firm growth. Using U.S. data on narrowly defined industries that permit a distinction between price and quantity, Foster et al. (2008) examine the separate contributions of demand and productivity for firm performance, finding that demand variation is the dominant driver of firm

*Manuscript received February 2019; revised August 2020.

We thank seminar and conference participants at Barcelona GSE Summer Forum, Bonn, Carlos III Madrid, DIW Berlin, Bristol, Dortmund, EEA-ESEM (Geneva), Essex, Frankfurt, IBS Warsaw, IHS Vienna, Kent, Manchester, Minneapolis Fed (NBER Conference), Nuremberg, NUS Singapore, NYU Abu Dhabi (Global Macro Workshop), Philadelphia Fed, SED (Toulouse), Tilburg, Zurich, and Verein für Socialpolitik (Basel) for helpful comments. We are grateful to Aleks Berentsen, Carlos Carrillo-Tudela, Alex Clymo, Leena Rudanko, three anonymous referees and the editor for numerous useful comments, and to Michael Rössner at the Statistical Office of the State of SachsenAnhalt for helpful advice. We thank the German Research Foundation (Grant No. KA 1519/8) for financial support. Please address correspondence to: Leo Kaas, Department of Money and Macroeconomics Goethe University Frankfurt Theodor-W.-Adorno-Platz 360629 Frankfurt Germany. E-mail: kaas@wiwi.uni-frankfurt.de.

\footnotetext{
${ }^{1}$ Search and matching frictions in the labor market have been introduced into the Hopenhayn-Rogerson model framework by, for example, Acemoglu and Hawkins (2014), Cooper et al. (2007), Elsby and Michaels (2013), Fujita and Nakajima (2016), Kaas and Kircher (2015), and Schaal (2017).
}

(C) 2021 The Authors. International Economic Review published by Wiley Periodicals LLC on behalf of the Economics Department of the University of Pennsylvania and the Osaka University Institute of Social and Economic Research Association

This is an open access article under the terms of the Creative Commons Attribution License, which permits use, distribution and reproduction in any medium, provided the original work is properly cited. 
growth and firm survival. ${ }^{2}$ Hottman et al. (2016) use price and sales information from scanner data to infer the sources of firm heterogeneity on the basis of a structural model of monopolistic competition. They show that demand differences and demand variation (as reflected in time-varying "firm appeal" and "product appeal" parameters) are a more important source of cross-sectional variation of sales and firm growth than are markups or cost heterogeneity. ${ }^{3}$

This article aims to understand the respective roles of demand and supply for firm dynamics and the labor market. To this end, we develop an equilibrium model with heterogeneous firms producing differentiated products and frictions in product and labor markets. We calibrate the model to match features of price and output adjustments of German manufacturing firms during the period 1995-2014. In particular, exogenous, persistent processes of firm-specific demand and productivity are calibrated to match the within-firm dynamics of prices and physical labor productivity. The quantitative model serves three purposes. First, we demonstrate how product market frictions (PMFs) matter for replicating quantitatively reasonable employment dynamics. Second, we quantify the importance of supply and demand for firm dynamics. Third, we use the model to explore the effects of aggregate first- or second-moment shocks to either demand or productivity and relate these findings to the business-cycle features in our data.

In Section 2, we build an equilibrium model in which heterogeneous firms compete for workers in a frictional labor market and simultaneously compete for retail buyers in a frictional product market. Demand (customer tastes) and physical productivity are firm-specific state variables, and idiosyncratic shocks to either of these variables have distinct implications for the price, output, and employment adjustments of a firm. Search frictions in labor and product markets imply that firms need to adjust their workforce as well as their customer base slowly over time. We show that due to PMFs, firm-specific demand and productivity shocks have a differential impact on firms' labor market adjustments. In particular, the extent of matching frictions in the product market crucially matters for a firm's employment response to productivity shocks, which is generally weaker when firms are more demand constrained. ${ }^{4}$

In Section 3, we calibrate this model to account for the joint dynamics of output and prices at the nine-digit product level in an administrative panel of manufacturing firms in Germany, which also contains information on employment and working hours. We use the product-level information on quantity and sales values to construct a firm-level price index and to measure quantity labor productivity (QLP). Idiosyncratic demand and productivity shocks are calibrated to match the firm-level dynamics of prices and quantity productivity in our data. Various parameters about product and labor market search frictions are calibrated to match recruitment and sales expenditures and worker and customer turnover rates. Importantly, the elasticity of the product market matching function determines how tightly firms are demand constrained and hence how quickly they adjust employment in response to productivity shocks. Indeed, we show that our model without product market frictions would generate too volatile employment dynamics when firms face empirically plausible shocks to demand and productivity. It would also generate a too strong comovement between employment and productivity.

We then examine the separate contributions of demand and productivity shocks for firm dynamics. They obviously play rather distinct roles for the output and price adjustments of

\footnotetext{
2 The quinquennial manufacturing census data they use does not permit them to study the dynamics of firms over time. Although there are no significant productivity differences across firms of different ages, younger firms charge lower prices than incumbents which suggests that these firms attempt to build a customer base (relationship capital). This idea motivates Foster et al. (2016) to build a structural econometric model of firm dynamics in which product demand stochastically adjusts slowly as firms actively expend resources to build a customer base.

${ }^{3}$ Argente et al. (2020) use similar data and show that most products are rather short-lived while firm appeal (i.e., demand) and product scope are the dominant factors of firm growth.

${ }^{4}$ Search frictions in the product market are one way to think about costly customer acquisition. Another approach would consider information dissemination and customer awareness as in Dinlersoz and Yorukoglu (2012) or Perla (2019).
} 
firms. Indeed, our model generates the empirical negative comovement between firm-level prices and output, an untargeted moment, which is ultimately driven by productivity shocks. Both demand and productivity shocks are quantitatively important for the employment adjustments of firms for which productivity plays a slightly more prominent role. In the absence of productivity shocks (demand shocks), job destruction at continuing firms would fall by $55 \%(42 \%)$. Over a third of unemployment is induced by either one of these two forces.

Finally, we examine the impact of different aggregate shocks on the economy. We compare declines in average productivity or demand, on the one hand, as well as increases in the uncertainty of productivity or demand, on the other hand. Shocks to the first moments of either productivity or demand do not generate quantitatively large responses of employment and they do not induce countercyclical dispersions of firm growth that we document in our data. The lack of labor market amplification is a result of our calibration strategy which sets the flow income value during unemployment to match a reasonable replacement rate of unemployment benefits, thereby generating a relatively large surplus value of a job. With a different small surplus calibration, the labor market response of first-moment shocks to productivity or demand would be larger, and both these shocks would also induce (small) countercyclical responses of price and output growth dispersion.

We further feed into our model shocks to the second moment of demand or productivity. An increase of demand uncertainty induces sizable declines in output and employment, together with a rise of price and output growth dispersion. Higher productivity uncertainty, on the other hand, cannot generate the comovement of aggregate output and employment. Likewise, productivity uncertainty shocks do not generate recessionary responses when product markets are frictionless. Based on these findings, we conclude that higher demand uncertainty is a plausible feature of recessionary episodes.

Related to our work are several recent contributions that introduce product market search frictions into macroeconomic models. Generally, search in product markets is meant to capture the observation that firms spend substantial time and resources for sales and marketing activities in order to attract customers. ${ }^{5}$ In the presence of these frictions, Bai et al. (2019) and Michaillat and Saez (2015) argue that aggregate demand shocks play a more prominent role than aggregate technology shocks. Kaplan and Menzio (2016), Petrosky-Nadeau and Wasmer (2015), and Den Haan (2013) combine frictions in product and labor markets, introducing new mechanisms for business-cycle dynamics. Albrecht et al. (2013), Paciello et al. (2019), and Shi (2016) examine price variability and sales policies in equilibrium models of product market search in which the customer base is a state variable. Unlike our article, none of these contributions addresses firm heterogeneity and the role of firm-specific demand.

Firms in our model employ multiple workers and accumulate a customer base with multiple customers. In these respects, our model closely relates to Gourio and Rudanko (2014), who study customer acquisition as a costly and time-consuming process, as well as Kaas and Kircher (2015), who describe the hiring process under convex labor adjustment costs. Both papers use competitive search as in Moen (1997) so that firms use lower product prices to attract more customers or higher wages to attract more workers. Our article combines these ingredients to develop a unified framework in which demand and productivity variation matters differentially for the dynamics of firms. ${ }^{6}$ Different from other competitive-search environments, equilibrium in our model is not socially efficient which is due to the presence of monopolistically competitive firms. Nonetheless, we show that optimal firm policies can be characterized in a fairly tractable way as solutions to a joint-surplus maximization problem.

Our finding that uncertainty shocks help to generate plausible aggregate dynamics is in accordance with a recent literature on the role of uncertainty in macroeconomics. For

\footnotetext{
${ }^{5}$ In the United States, marketing expenditures are as high as 7.7\% of GDP (Arkolakis, 2010).

${ }^{6}$ Relatedly, Roldan and Gilbukh (2021) introduce idiosyncratic productivity risk in a model similar to Gourio and Rudanko (2014) which they calibrate in order to match features of price and sales dispersion from scanner data, to study the response of markups to aggregate shocks, among others. Unlike us, they do not consider firm-specific demand shocks or labor market features.
} 
instance, Bloom (2009), Bloom et al. (2018), and Bachmann and Bayer (2014) argue that time-varying uncertainty improves the fit of macroeconomic models with heterogeneous firms. Schaal (2017) considers a heterogeneous-firm model with labor market search, showing that uncertainty shocks help to understand the volatility of aggregate unemployment. In these articles, uncertainty shocks are introduced as increases in the volatility of idiosyncratic (revenue) productivity. Our contribution is that we are able to distinguish between demand uncertainty and (physical) productivity uncertainty as separate influence factors for the overall uncertainty at the firm level. We show that demand uncertainty is a more relevant feature of the business cycle than productivity (or cost) uncertainty. ${ }^{7}$

Our work further relates to an empirical literature which investigates the dispersion and dynamics of firm-level prices and productivity. While Abbott (1991) and Foster et al. (2008) document dispersion of producer prices in specific industries, Carlsson and Skans (2012) and Carlsson et al. (2021) use Swedish firm-level data for the manufacturing sector, finding that unit labor costs are transmitted less than one-to-one to output prices, and that much of the variation in output prices remains unexplained by productivity shocks. Furthermore, they find that employment responds negligibly to productivity shocks, whereas permanent demand shocks are the main driving force of employment adjustment. Pozzi and Schivardi (2016) use data for Italian manufacturing firms to identify demand and total factor productivity (TFP) shocks as separate factors driving firm growth on the basis of a frictionless model. They find that the firms' responses to these shocks are limited which suggests the importance of adjustment frictions.

\section{THE MODEL}

In this section, we build a canonical model that describes the dynamics of firms in frictional product and labor markets. The model includes a representative household, retailers, and firms. The household buys differentiated goods in a competitive market from retailers and supplies labor in a frictional labor market to firms. Retailers buy goods in a frictional product market from firms. All retailers and firms are owned by the representative household.

In the product market, firms compete for retailers ("buyers") via costly sales activities and by offering discounts on their products, which helps to accumulate a customer base. In the labor market, firms build up a workforce by spending resources on recruitment and by offering long-term contracts to new hires. Firms adjust their customer base and their employment stock in response to idiosyncratic demand and productivity shocks. Search in both markets is competitive: workers and buyers direct their search toward particular wage or price offers, trading off higher matching rates against lower match values.

We describe a stationary equilibrium in which search values of buyers and workers are constant over time, whereas individual firms' employment and output grow or shrink, depending on their idiosyncratic productivity and demand states. We then establish a theorem which describes a tractable equilibrium characterization by a joint-surplus maximization problem.

\subsection{The Environment.}

2.1.1. Representative household. The infinitely lived household consumes differentiated goods produced by firms as well as a separate numeraire good. Utility of the household is

$$
\sum_{t} \beta^{t}\left[e_{t}+u\left(C_{t}\right)\right], \quad \text { where } C_{t}=\left(\int\left[y_{t}(f) c_{t}(f)\right]^{\theta} d \mu_{t}(f)\right)^{1 / \theta}
$$

\footnotetext{
${ }^{7}$ Different from this article, Basu and Bundick (2017) and Leduc and Liu (2016) introduce demand uncertainty as time-varying volatility of the household's discount factor in New-Keynesian Dynamic Stochastic General Equilibrium (DSGE) models.
} 
$e_{t}$ is consumption of the numeraire good, $u$ is a concave utility function, and $\beta$ is the household's discount factor. $C_{t}$ is a consumption aggregator which integrates over the measure $\mu_{t}$ of active firms $f$ whose output the household consumes in $c_{t}(f)$ units. $y_{t}(f)$ are idiosyncratic (firm-specific and time-varying) preference parameters which reflect, for instance, firm- or product-specific tastes or brand values. ${ }^{8}$ Parameter $\theta \in(0,1)$ defines the substitution elasticity $(1-\theta)^{-1}>1$ between different products. In a stationary equilibrium, $C_{t}=C$ is a constant. All prices, wages, and costs defined below are expressed in units of the numeraire good.

2.1.2. Workers. There is a constant stock $\bar{L}$ of workers who are members of the household. A worker can be either employed at a firm or unemployed. An unemployed worker earns $b$ units of the numeraire good. Only unemployed workers search for jobs.

2.1.3. Retailers. There is a (potentially unlimited) number of retailers which buy consumption goods from firms and sell them to households at competitive retail prices. Retailers can be either attached to the customer base of a firm or unattached. In the former case, the retailer can buy the output good of this firm up to a fixed (unit) quantity. Selling (possibly smaller) quantities of this good to the household is costless; hence the profit of an attached retailer is simply the difference between the retail price and the purchase price. Alternatively, retailers are unattached in which case they may search for purchases from firms. Search involves payment of $\kappa>0$ units of the numeraire good; once matched to a firm, the retailer can buy up to one unit of the good produced by the firm per period until a separation occurs. ${ }^{9}$

2.1.4. Production firms. A firm with $L$ workers produces $x L$ units of its unique output good. ${ }^{10} x$ is the firm's idiosyncratic productivity. Shocks to $x$ stand for any type of supply-side events such as technology changes or (unmodeled) price changes of factor inputs besides labor. If the firm has $B$ retail buyers, it sells $B$ units of output in the current period, given the unit purchase constraint. Because the good is nonstorable, the firm is naturally constrained by $B \leq x L$ in any given period. If that inequality is strict, the firm wastes some of its output. ${ }^{11}$

2.1.5. Retail market. After a firm sells $B$ units of its output to retailers, the latter sell these goods to the household at competitive retail prices. This implies that consumption of the firm's output is $c=B$, while the competitive retail price equals the household's marginal rate of substitution between the firm's output good and the numeraire good which is $u^{\prime}(C) C^{1-\theta} y^{\theta} B^{\theta-1}$ where $y$ is the firm-specific demand state. To simplify notation, write $M \equiv$ $u^{\prime}(C) C^{1-\theta}$ (a constant in steady state) which implies that the retail price of a firm's product with demand state $y$ and customer base of size $B$ is equal to $p^{r}=M y^{\theta} B^{\theta-1}$.

2.1.6. Shocks. Both idiosyncratic states $x$ and $y$ follow a Markov process on a finite state space. We write $z=(x, y) \in Z$ and denote $\pi\left(z_{+} \mid z\right)$ the transition probability from $z$ to $z_{+}$. For a firm of age $a$, we write $z^{a}=\left(z_{0}, \ldots, z_{a}\right)$ for the shock history from the entry period (firm age zero) up to the current period (firm age $a) \cdot \pi^{a}\left(z^{a}\right)$ denotes the unconditional probability of that history event.

\footnotetext{
${ }^{8}$ These are the counterparts of the firm and product appeal parameters of Hottman et al. (2016).

${ }^{9}$ With this simple linear technology, retail firms can also be interpreted as collections of multiple purchase connections to production firms where each connection allows the purchase of a fixed (one unit) quantity of the firm's output. Any expansion of purchase connections requires the payment of the fixed search cost.

${ }^{10} \mathrm{In}$ an earlier version of this article, we assume that firms produce perfect substitutes $(\theta=1)$ while revenue is concave due to decreasing returns in production. It is straightforward to combine both features so that firm size is constrained both by curvature in demand and in production.

${ }^{11}$ It is a straightforward extension to introduce inventories at the computational cost of adding another state variable to the firm's problem.
} 
2.1.7. Recruitment and sales activities. For recruitment and sales, the firm spends $r(R)$ and $s(S)$ units of the numeraire good, respectively, where $R$ and $S$ measure recruitment and sales effort. Both cost functions are increasing and convex.

2.1.8. Labor market search. Search in the labor market is competitive (cf., Moen, 1997). Recruiting firms offer long-term contracts to new hires, understanding that contracts which are more valuable to workers attract more job applicants and hence speed up hiring. Firms and workers meet in submarkets that differ by the offered contract values. In a given submarket, a firm hires $m(\lambda) \leq \lambda$ workers per unit of recruitment effort, where $\lambda$ measures unemployed workers per unit of recruitment effort in the submarket, and $m$ is a strictly increasing and concave function. Hence, $m(\lambda) / \lambda$ is the probability that an unemployed worker finds a job in this submarket, a decreasing function of $\lambda$. An employment contract specifies wage payments and separation probabilities contingent on realizations of firm-specific shocks. We write $\mathcal{C}^{a}=\left(w^{a}\left(z^{k}\right), \delta_{w}^{a}\left(z^{k+1}\right)\right)_{k \geq a}$ for the employment contract of a worker who is hired by a firm of age $a . w^{a}\left(z^{k}\right)$ is the wage that the worker earns when the firm has age $k \geq a$, conditional on the shock history $z^{k}$ and conditional on staying employed at this firm. $\delta_{w}^{a}\left(z^{k+1}\right)$ is the probability to separate from the firm in event history $z^{k+1}$ with $k+1>a$.

2.1.9. Product market search. Search in the product market is also competitive, but here firms cannot commit to long-term contracts. ${ }^{12}$ Instead, firms that aim to expand the customer base offer discount prices $p^{d}$ to new buyers. In all subsequent periods, attached retailers continue purchasing at this firm, but anticipate that the firm charges the reservation price $(=$ retail price) $p^{r}$ which makes the retailer exactly indifferent between buying and not buying. Firms understand that lower discount prices attract more searching retailers and hence allow firms to expand the customer base faster. Unattached retailers and selling firms are matched in submarkets which differ by the posted discount prices. Per unit of sales effort, the firm attracts $q(\varphi) \leq \varphi$ new buyers, where $\varphi$ is the measure of unattached buyers per unit of sales effort in the submarket, and $q$ is an increasing and concave function. An unattached buyer searching for purchases is successful with probability $q(\varphi) / \varphi$, which is a decreasing function of $\varphi$.

2.1.10. Entry, separations, and exit. New firms can enter the economy at cost $K>0$ with zero workforce and zero customer base. They draw an initial productivity and demand state $z_{0}=\left(x_{0}, y_{0}\right)$ from probability distribution $\pi^{0}$. Any existing firm, depending on its supply and demand shocks, separates from workers according to the contractual commitments. Separated workers can search for jobs in the same period. The firm may also decide not to serve some of its attached retailers who then leave the firm's customer base. Workers quit the job into unemployment with exogenous probability $\bar{\delta}_{w}$, and retailers leave the customer base of a firm with exogenous probability $\bar{\delta}_{b}$. This implies that the actual customer churn rate is bounded below by $\delta_{b} \geq \bar{\delta}_{b}$. Likewise, the contractual state-contingent worker separation rates are bounded below by $\delta_{w} \geq \bar{\delta}_{w}$. At the end of the period, any firm exits with probability $\delta$ in which case all its workers enter the unemployment pool and all its buyers become unattached.

2.1.11. Timing. The timing within a period is as follows: First, firm-specific demand and productivity shocks are realized. Second, some workers and buyers separate from firms. Third,

\footnotetext{
12 The assumption that firms offer long-term contracts to workers though not to retailers is intended to reflect realistic features of worker-firm and customer-firm relationships. Although long-term contracts with customers are common in some industries, they tend to be rather short. For German manufacturing firms, Stahl (2010) finds that although $50 \%$ of sales are undertaken in written contracts, the average contract duration is just nine months. With our annual calibration, the absence of price commitment seems a plausible assumption. In Appendix A.1, we describe an alternative pricing assumption with long-term contracts and no price discrimination between first-time buyers and repeat buyers.
} 
firms search for new hires and buyers. Fourth, production takes place, workers are paid, and goods are sold. Fifth, firms exit with probability $\delta$.

2.2. Competitive-Search Equilibrium. We describe a stationary equilibrium in which search values of workers and buyers, as well as the distributions of workers and buyers across firm types, are constant over time. Any firm's policy only depends on the idiosyncratic shock history $z^{a}$ where $a$ is the firm's age. Hence, we identify the different firm types with $z^{a}$.

2.2.1. Workers. Let $U$ denote the value of an unemployed worker and let $W\left(\mathcal{C}^{a}, z^{k}\right)$ denote the value of an employed worker in contract $\mathcal{C}^{a}$ at firm $z^{k}$ with $k \geq a$. These values represent the marginal contribution of the worker to the representative household's utility. Unemployed workers observe the set of contracts $\mathcal{C}^{a}$ at firm types $z^{a}$ and the corresponding market tightness $\lambda$ in the submarkets in which value-equivalent contracts are offered. An unemployed worker's Bellman equation is

$$
U=\max _{W\left(\mathcal{C}^{a}, z^{a}\right), \lambda} \frac{m(\lambda)}{\lambda} W\left(\mathcal{C}^{a}, z^{a}\right)+\left(1-\frac{m(\lambda)}{\lambda}\right)[b+\beta U],
$$

where maximization is over all submarkets $\left(W\left(\mathcal{C}^{a}, z^{a}\right), \lambda\right)$. With probability $m(\lambda) / \lambda$, the worker finds employment in which case the continuation value is $W\left(\mathcal{C}^{a}, z^{a}\right)$. Otherwise the worker earns unemployment income $b$ and remains unemployed to the next period.

The employment value $W\left(\mathcal{C}^{a}, z^{k}\right)$ satisfies the Bellman equation

$$
W\left(\mathcal{C}^{a}, z^{k}\right)=w^{a}\left(z^{k}\right)+\beta(1-\delta) \mathbb{E}_{z^{k}} W^{\prime}\left(\mathcal{C}^{a}, z^{k+1}\right)+\beta \delta U
$$

This worker earns the contractual wage $w^{a}\left(z^{k}\right)$ in the current period. At the end of the period, the firm exits with probability $\delta$ in which case the worker becomes unemployed. Otherwise the worker stays employed to the next period which yields continuation value $W^{\prime}\left(\mathcal{C}^{a}, z^{k+1}\right)$ where the prime indicates the employment value before the firm separates from workers, that is,

$$
W^{\prime}\left(\mathcal{C}^{a}, z^{k+1}\right)=\left[1-\delta_{w}^{a}\left(z^{k+1}\right)\right] W\left(\mathcal{C}^{a}, z^{k+1}\right)+\delta_{w}^{a}\left(z^{k+1}\right) U
$$

With contractual separation probability $\delta_{w}^{a}\left(z^{k+1}\right)$, the worker leaves the firm and can search for employment in the same period (continuation utility $U$ ). Otherwise the worker stays employed with continuation utility $W\left(\mathcal{C}^{a}, z^{k+1}\right)$.

It is convenient to define the option value of search in submarket $(W, \lambda)$ by

$$
\bar{\rho}(W, \lambda) \equiv \frac{m(\lambda)}{\lambda}(W-b-\beta U)
$$

Then, the flow utility value of unemployment satisfies

$$
(1-\beta) U=b+\rho,
$$

where $\rho \equiv \max \bar{\rho}\left(W\left(\mathcal{C}^{a}, z^{a}\right), \lambda\right)$ is the maximal search value over all submarkets. It follows that any contract that attracts unemployed workers (i.e., $\lambda>0$ ) yields the same search value $\rho$.

2.2.2. Buyers. Unattached retailers can search for purchases at cost $\kappa>0$. They observe discount prices $p^{d}$ offered by firms of different types $(y, B)$, anticipating that this firm's output can be sold at retail price $p^{r}=M y^{\theta} B^{\theta-1}$. A newly matched retailer makes profit $p^{r}-p^{d}$ in the first period and anticipates that the firm charges reservation (retail) prices in all subsequent 
periods. Therefore, the buyer's continuation value beyond the matching period is zero. Let $\varphi$ denote buyer-to-sales-effort ratio in a generic submarket with matching probability $q(\varphi) / \varphi$. The expected gain from searching must equal the search cost:

$$
\kappa=\max _{\left(p^{d}, p^{r}, \varphi\right)} \frac{q(\varphi)}{\varphi}\left[p^{r}-p^{d}\right]
$$

where maximization is over all submarkets $\left(p^{d}, p^{r}, \varphi\right)$. Any discount price that attracts new buyers (i.e., $\varphi>0$ ) yields the same search value $\kappa$. It follows that discount prices are linked to market tightness $\varphi$ via

$$
p^{d}=p^{r}-\frac{\kappa \varphi}{q(\varphi)}
$$

2.2.3. Firms. A firm of type $z^{a}$ takes as given the workers hired in earlier periods, $L^{\tau}, \tau=$ $0, \ldots, a-1$, together with their respective contracts $\mathcal{C}^{\tau} .{ }^{13}$ It also takes as given the existing stock of the customer base $B_{-}$. Hence, the firm's state vector is $\sigma=\left[\left(L^{\tau}, \mathcal{C}^{\tau}\right)_{\tau=0}^{a-1}, B_{-}, z^{a}\right]$. Let $J_{a}(\sigma)$ denote the value of the firm at the beginning of the period. The firm chooses recruitment policy $\left(\lambda, R, \mathcal{C}^{a}\right)$ and sales policy $\left(\delta_{b}, \varphi, S, p^{d}, p^{r}\right)$ to solve the problem

(6)

$$
J_{a}(\sigma)=\max _{\left(\lambda, R, \mathcal{C}^{a}\right),\left(\delta_{b}, \varphi, S, p^{d}, p^{r}\right)}\left\{p^{r} B_{-}\left(1-\delta_{b}\right)+p^{d} q(\varphi) S-W-r(R)-s(S)+\beta(1-\delta) \mathbb{E} J_{a+1}\left(\sigma_{+}\right)\right\}
$$

subject to

$$
\begin{gathered}
\sigma_{+}=\left[\left(L^{\tau+}, \mathcal{C}^{\tau}\right)_{\tau=0}^{a}, B, z^{a+1}\right] \mathcal{C}^{a}=\left(w^{a}\left(z^{k}\right), \delta_{w}^{a}\left(z^{k+1}\right)\right)_{k \geq a} \delta_{w}^{a}(.) \geq \bar{\delta}_{w}, \\
L^{\tau+}=\left(1-\delta_{w}^{\tau}\left(z^{a}\right)\right) L^{\tau}, \tau=0, \ldots, a-1, L^{a+}=m(\lambda) R \\
W=\sum_{\tau=0}^{a} w^{\tau}\left(z^{a}\right) L^{\tau+}, \\
B=B_{-}\left(1-\delta_{b}\right)+q(\varphi) S, \delta_{b} \geq \bar{\delta}_{b}, \\
B \leq x L, L=\sum_{\tau=0}^{a} L^{\tau+}, \\
\rho=\bar{\rho}\left(W\left(\mathcal{C}^{a}, z^{a}\right), \lambda\right) \text { if } \lambda>0
\end{gathered}
$$

The firm's problem (6) is to maximize revenue from sales to attached and new buyers minus expenditures for wages, sales, and recruitment costs, plus the expected continuation profit.

\footnotetext{
${ }^{13}$ Without loss of generality, all workers hired by a firm of a given type are hired in the same contract, which is an optimal policy of the firm (see Kaas and Kircher, 2015, for a formal argument).
} 
The firm is committed to separation rates $\delta_{w}^{\tau}\left(z^{a}\right)$ for workers hired in previous periods $\tau<a$. For workers hired in this period, the firm commits to future separation rates, $\delta_{w}^{a}\left(z^{k+1}\right) \geq \bar{\delta}_{w}$, $k \geq a$. Together with wages $w^{a}($.$) , they define the contract \mathcal{C}^{a}$ offered to new hires. Equations (8) say how employment in different worker cohorts evolves over time. Equation (9) states the wage bill of the firm. Equation (10) says how the firm's customer base evolves. Because the firm is not committed in the product market, it decides buyer separation rates $\delta_{b} \geq \bar{\delta}_{b}$ (if required) freely. ${ }^{14}$ Condition (11) says that the firm cannot sell more than what it produces with its current workforce $L$. Regarding wage contracts offered to new hires $\mathcal{C}^{a}$, as well as discount price offers $p^{d}$ to new buyers, the firm respects the search incentives of workers and buyers, as expressed by constraints (12) and (13). That is, to attract more workers per recruitment effort (higher $\lambda$ ), the firm needs to offer a more attractive employment contract. Likewise, to attract more buyers per sales effort (higher $\varphi$ ), the firm needs to offer a lower discount price. The last equation in (13) says that the firm optimally charges the reservation price $p^{r}$ on attached buyers.

2.2.4. Equilibrium. We can express all firm policy functions defined above to depend on the firm's history $z^{a}$, ignoring the dependence on precommitted contracts and worker cohorts. This is feasible because such firm state variables evolve endogenously as functions of the firm's past shocks and policies. Hence, all firm policies (in stationary equilibrium) are functions of the idiosyncratic state history. For a firm of type $z^{a}$, write $\lambda\left(z^{a}\right)$ and $R\left(z^{a}\right)$ for the recruitment policy, $\varphi\left(z^{a}\right)$ and $S\left(z^{a}\right)$ for the sales policy, and so on. ${ }^{15}$ Further define

$$
L\left(z^{a}\right)=\sum_{\tau=0}^{a} L^{\tau}\left(z^{a}\right)
$$

$$
B\left(z^{a}\right)=B\left(z^{a-1}\right)\left[1-\delta_{b}\left(z^{a}\right)\right]+q\left(\varphi\left(z^{a}\right)\right) S\left(z^{a}\right)
$$

for the stocks of workers and buyers in firm history $z^{a}$, where $L^{\tau}\left(z^{a}\right)=L^{\tau}\left(z^{a-1}\right)\left[1-\delta_{w}^{\tau}\left(z^{a}\right)\right]$ if $a>\tau, L^{a}\left(z^{a}\right)=m\left(\lambda\left(z^{a}\right)\right) R\left(z^{a}\right)$, and $B\left(z^{-1}\right)=0$. Furthermore, there are

$$
N\left(z^{a}\right)=N_{0}(1-\delta)^{a} \pi^{a}\left(z^{a}\right)
$$

firms of type $z^{a}$ when $N_{0}$ is the mass of entrant firms in any period. We are now ready to define the stationary equilibrium.

Definition 1. A stationary competitive-search equilibrium is a list of value functions $U, W$, $W^{\prime}, J_{a}$, firm policies $\lambda, R, \varphi, S, \delta_{b}, \mathcal{C}^{a}=\left(w^{a}(),. \delta_{w}^{a}().\right),\left(L^{\tau}\right)_{\tau=0}^{a}, L, B, p^{d}, p^{r}$ which are all functions of the firm type $z^{a}$, entrant firms $N_{0}$, aggregate consumption $C$ with $M=u^{\prime}(C) C^{1-\theta}$, and a search value $\rho$ such that:

(a) Workers' value functions $U, W, W^{\prime}$ and the search value $\rho$ describe optimal search behavior, Equations (1)-(4).

(b) Retailers search optimally, Equation (5), and aggregate consumption is given by

$$
C=\left[\sum_{z^{a}} N\left(z^{a}\right)\left(y_{a} B\left(z^{a}\right)\right)^{\theta}\right]^{1 / \theta} .
$$

\footnotetext{
${ }^{14}$ Customer separations can only be optimal in response to adverse productivity shocks when the cost of employing (or hiring) $L=\left(B_{-}\left(1-\bar{\delta}_{b}\right)\right) / x$ workers exceeds the revenue $p^{r} B_{-}\left(1-\bar{\delta}_{b}\right)$ plus the discounted continuation value of starting the next period with $B_{-}\left(1-\bar{\delta}_{b}\right)$ customers.

${ }^{15}$ With abuse of notation, these functions are not indexed by the firm's age.
} 
(c) Firms' value functions $J_{a}$ and policy functions solve problems (6)-(13), and $L(),. B($.$) ,$ and $N($.$) evolve according to (14), (15), and (16).$

(d) Firm entry is optimal. That is, $N_{0}>0$ and

$$
K=\sum_{z^{0}} \pi^{0}\left(z^{0}\right) J_{0}\left(0, z^{0}\right)
$$

(e) Aggregate resource feasibility:

$$
\bar{L}=\sum_{z^{a}} N\left(z^{a}\right)\left\{L\left(z^{a}\right)+\left[\lambda\left(z^{a}\right)-m\left(\lambda\left(z^{a}\right)\right)\right] R\left(z^{a}\right)\right\}
$$

Aggregate resource feasibility (e) requires that any worker either belongs to the workforce $L\left(z^{a}\right)$ at one of $N\left(z^{a}\right)$ firms of type $z^{a}$ or that the worker is unsuccessfully searching for a job in one of the submarkets where firms of type $z^{a}$ search: precisely, $\lambda\left(z^{a}\right) R\left(z^{a}\right)$ workers are searching for employment per firm of type $z^{a}$, and share $1-m\left(\lambda\left(z^{a}\right)\right) / \lambda\left(z^{a}\right)$ of these workers are not successful and hence remain unemployed. In Appendix A.1, we show how the aggregate resource constraint for the numeraire good can be derived using the budget constraint of the representative household and profits of firms.

2.3. Characterization. The competitive-search equilibrium permits a tractable solution which builds on the maximization of the joint surplus of a firm together with all workers and retail buyers linked to the firm. This problem ignores the impact of the firm's production on the representative household's consumer surplus. Therefore, as is well-known in environments with monopolistically competitive firms, equilibrium is not socially efficient. ${ }^{16}$

Write $G\left(L_{-}, B_{-}, z\right)$ for the surplus of a firm with productivity and demand state $z=(x, y)$ that begins a period with $L_{-}$workers and $B_{-}$buyers. This surplus includes the value that the firm generates for its owners as well as to all workers and retail buyers that are linked to the firm. It satisfies the recursion

$$
\begin{aligned}
G\left(L_{-}, B_{-}, z\right)=\max _{\left(\lambda, R, \delta_{w}\right),\left(\varphi, S, \delta_{b}\right)}\{ & M(y B)^{\theta}-(b+\rho) L-r(R)-s(S) \\
& \left.-\rho(\lambda-m(\lambda)) R-\kappa \varphi S+\beta(1-\delta) \mathbb{E}_{z} G\left(L, B, z_{+}\right)\right\}
\end{aligned}
$$

subject to

$$
\begin{aligned}
& L=L_{-}\left(1-\delta_{w}\right)+m(\lambda) R, B=B_{-}\left(1-\delta_{b}\right)+q(\varphi) S \\
& B \leq x L, \delta_{w} \geq \bar{\delta}_{w}, \delta_{b} \geq \bar{\delta}_{b}
\end{aligned}
$$

The joint surplus of a firm is the firm's revenue $p^{r} B=M(y B)^{\theta}$, minus the opportunity costs of employment, $(b+\rho) L$, recruitment and sales costs, $r($.$) and s($.$) , opportunity costs of job$ search for unemployed workers who unsuccessfully try to find employment at this firm, $\rho(\lambda-$ $m(\lambda)) R$, and search costs of new retailers aiming to join the customer pool of this firm, $\kappa \varphi S$. These search costs are incurred by $q(\varphi) S$ new buyers attracted by the firm, but also by $(\varphi-$ $q(\varphi)) S$ unsuccessful retailers who remain unmatched at the end of the period.

\footnotetext{
${ }^{16}$ Social optimality only obtains in the limiting case of perfect substitutes $(\theta \rightarrow 1)$. We prove this result in a previous version of this article where we set $\theta=1$ and allow for decreasing returns in production.
} 
Proposition 1. Suppose that G solves the recursive joint-surplus maximization problem (20) and that

$$
K=\sum_{z} \pi^{0}(z) G(0,0, z)
$$

holds. Furthermore, let $N\left(z^{a}\right), L\left(z^{a}\right)$, and $B\left(z^{a}\right)$ be defined recursively for given entry measure $N_{0}$ and iteration over the policy functions of problem (20), and suppose that the aggregate resource constraint (19) holds and that $M=u^{\prime}(C) C^{1-\theta}$ with aggregate consumption given by (17). Then there exists a stationary competitive-search equilibrium with identical firm policy functions as those described by (20), aggregate consumption $C$, and workers' search value $\rho$.

The characterization by a joint-surplus maximization problem greatly facilitates the computation of an equilibrium. Given a guess for $\rho$ (search value) and $M$ (marginal utility), solutions of (20) can be calculated by standard recursive methods. Updates for $\rho$ and $M$ are then obtained by using the entry condition (21) and the consumption aggregator (17). ${ }^{17}$ All wages and prices can then be calculated using the respective search values of workers and retailers; see Appendix A.1 for details.

Proposition 1 extends welfare results for competitive-search economies (cf., Moen, 1997) to an environment with monopolistically competitive firms and two-sided market frictions. ${ }^{18}$ Kaas and Kircher (2015) prove similar results for multiworker firms in an environment without PMFs (and without monopolistic competition). Different from these well-known results, the competitive-search equilibrium in our model is not efficient. Instead, it maximizes the joint surplus of firms, workers, and retail buyers, without taking the impact on consumer surplus into account.

2.4. Product and Labor Market Interactions. To illustrate the role of market frictions for the impact of productivity and demand shocks, consider a one-period version of this model. Firms enter at cost $K$ after which they draw productivity and demand states $(x, y)$ and choose recruitment and sales policies to attract customers and workers. Using the characterization of Proposition 1, each firm maximizes the joint surplus,

$$
M[y q(\varphi) S]^{\theta}-b m(\lambda) R-\rho \lambda R-\kappa \varphi S-r(R)-s(S)
$$

subject to the constraint that all produced goods are sold, $x m(\lambda) R=q(\varphi) S$. As in the dynamic problem described above, joint surplus is the firm's revenue minus opportunity costs of workers and retailers, recruitment and sales costs. The four optimality conditions of this problem can be expressed as follows:

$$
\begin{gathered}
r^{\prime}(R)=\rho\left[\frac{m(\lambda)}{m^{\prime}(\lambda)}-\lambda\right], \\
s^{\prime}(S)=\kappa\left[\frac{q(\varphi)}{q^{\prime}(\varphi)}-\varphi\right], \\
M \theta(x y)^{\theta}[m(\lambda) R]^{\theta-1}-b=\frac{\rho}{m^{\prime}(\lambda)}+\frac{x \kappa}{q^{\prime}(\varphi)},
\end{gathered}
$$

\footnotetext{
${ }^{17}$ Specifically, if the value of an entrant is smaller (larger) than the entry cost, $\rho$ must be decreased (increased). With the measure of entrant firms $N_{0}$ backed out from (16) and (19), aggregate consumption can be calculated from (17) which yields an update for $M$.

${ }^{18}$ In random search models, efficiency in two-sided search markets is far from trivial; see Petrosky-Nadeau et al. (2020) on the derivation of a double Hosios condition in a model with random search in product and labor markets.
} 


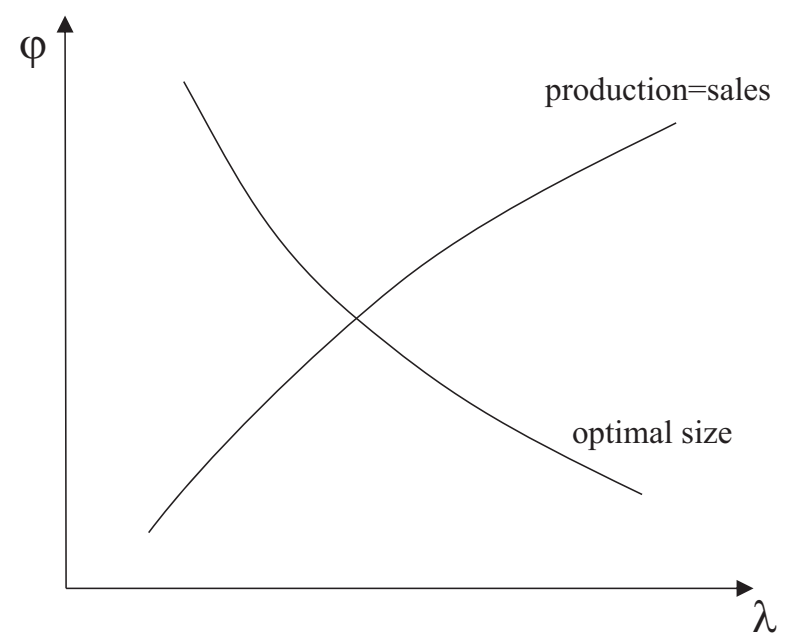

FIGURE 1

OPTIMAL HIRING AND SALES POLICIES

$$
x m(\lambda) R=q(\varphi) S
$$

Condition (22) says that across firms (which differ by $x$ and $y$ ) recruitment effort and matching rates are positively related: firms hire more by spending more on recruitment (higher $R$ ) and by offering higher wages, thus attracting more workers (higher $\lambda$, cf., Kaas and Kircher, 2015). Condition (23) expresses a similar relation in the product market: firms that spend more on sales also have lower discount prices (higher $\varphi$, cf., Gourio and Rudanko, 2014). ${ }^{19}$

Condition (24) determines the size of firms and is unique to this model with two-sided frictions. The left-hand side expresses the marginal joint worker-firm surplus, that is, marginal revenue net of the opportunity cost of work. The right-hand side is the marginal cost of employing one more worker and selling the output that this worker produces. It includes both the marginal cost of hiring the worker, $\rho / m^{\prime}(\lambda)$, and the marginal cost of attracting $x$ new customers which is $x \kappa / q^{\prime}(\varphi)$. Both marginal costs critically depend on matching frictions. For instance, if the elasticity of $q^{\prime}$ is large (in absolute value), marginal customer acquisition costs rise steeply with the magnitude of customer expansion as summarized by the buyer-to-saleseffort ratio $\varphi$. This is the case when product market congestion externalities on the side of sellers are larger. Likewise, if the elasticity of $m^{\prime}$ is larger, marginal hiring costs rise steeply with the total amount of hires. Taken together, the two cost terms in (24) reflect how tightly the firm is constrained in both markets. In technical terms, this condition defines a downwardsloping relation between the hiring indicator $\lambda$ (note again that recruitment effort $R$ increases in $\lambda$ via (22)) and the sales indicator $\varphi$ (which is positively linked to sales effort $S$ via (23)), see Figure 1. Intuitively, if the firm hires and hence produces more, marginal revenue falls (the price declines in the supply of the firm's good) and marginal hiring costs increase. In response, the firm cuts sales expenditures and sets a smaller discount on the producer price.

Condition (25) is the requirement that production equals sales. After inverting (22) and (23) for $R$ and $S$, this condition defines an increasing relation between the hiring indicator $\lambda$ and the sales indicator $\varphi$ (see Figure 1). Intuitively, if the firm hires and produces more, it requires more sales expenditures (and lower discount prices) to sell the additional output.

${ }^{19}$ Both conditions are exactly the same in the dynamic model. 
Jointly, the two conditions (24) and (25) determine how optimal hiring and sales policies depend on firm characteristics, in particular on the productivity and demand states $(x, y){ }^{20}$

The presence of PMFs crucially matters for the firm's response to productivity and demand shocks. With frictionless product markets, buyers' and sellers' search costs are zero, $\kappa=0$ and $s()=$.0 , and the firm's optimal size is determined by its hiring policy $(\lambda, R)$ which is the solution of (22) and (24) (without the last cost term). In this case, a 1\% increase of productivity $x$ has exactly the same impact on employment as a $1 \%$ increase of demand $y$. Likewise, the firm's revenue (price multiplied with output) responds identically to changes in $x$ and $y$. The same is true in the dynamic model with frictionless product markets: a shock to $x$ has the same impact on employment and revenue as a shock to $y$ in the same proportion would have. ${ }^{21}$

Matters are very different when PMFs come into play. An increase of demand (parameter $y$ ) induces the firm to hire more and to acquire more customers: the downward-sloping curve in Figure 1 shifts outward so that $\lambda$ and $\varphi$ increase. Hence, the firm's output, employment, and wage increase. Retail and producer prices are larger, while the discount on the producer price increases. Conversely, an increase of productivity (parameter $x$ ) unambiguously induces the firm to acquire more customers: $\varphi$ increases since both curves in Figure 1 shift up. Hence, output increases whereas retail and producer prices fall, in combination with a greater discount. However, the labor market response is generally ambiguous and depends on how tight the demand constraint binds. If the product market search externality is strong enough, the firm may even choose to decrease employment in response to a positive productivity change. This happens if the elasticity of $q^{\prime}$ is relatively large (i.e., the elasticity of $q$ is small) so that the downward-sloping curve in Figure 1 is relatively flat.

Generally, the presence of PMFs dampens the employment and output response to productivity shocks. We make use of this observation in the next section where we calibrate the product market matching function elasticity in line with the firms' employment variability that we measure in our firm-level data.

\section{QUANTITATIVE ANALYSIS}

In this section, we calibrate the model to match statistics of price and productivity dynamics of German manufacturing firms. We do this to achieve three goals: First, we demonstrate the importance of PMFs for the employment adjustments of firms. Second, we examine the quantitative role of demand and productivity for firm dynamics. Third, we use the model to explore the impact of aggregate shocks on macroeconomic outcomes which we compared with the cyclical features in our data. Before we do so, we describe our data and the calibration strategy.

3.1. Data and Measurement. This section describes the data and how we use them to construct firm-level measures of prices and QLP. Further details and descriptive statistics are contained in Appendix A.2. We use administrative firm data for Germany (Amtliche Firmendaten für Deutschland, AFiD), which are provided by the Research Data Centers of the Federal and State Statistical Offices. ${ }^{22}$ We work with the panel Industriebetriebe (manufacturing establishments) and the module Produkte for the years 1995-2014. The former is an annual panel which builds on monthly, quarterly, and annual census statistics covering all establishments in manufacturing, mining, and quarrying with 20 or more employees. These data contain annual information on employment, revenue, and wage bill, whereas working hours are available for

\footnotetext{
20 Three further conditions are needed to determine the equilibrium in this one-period model: free entry of firms and the labor market resource constraint determine the search value $\rho$ and the number of firms, and aggregate consumption determines $M=u^{\prime}(C) C^{1-\theta}$. These conditions are irrelevant for the cross-sectional variation of firm policies which is the focus of the discussion in this subsection.

${ }^{21}$ This statement trivially follows from problem (20) when $\kappa=0$ and $s()=$.0 .

${ }^{22}$ For more information and how to access the data, see Malchin and Voshage (2009) and the Web site of the Research Data Centers: http://www.forschungsdatenzentrum.de.
} 
a subsample of establishments. The module Produkte builds on quarterly production statistics and has recordings on quantities and revenues for nine-digit products for these establishments. We merge the two panels in order to construct a matched establishment-product panel. We deflate nominal variables to 2010 euros using the GDP deflator.

We drop establishments that do not operate throughout a given year or that report to employ fewer than 20 employees. We further drop products that are measured in different units across establishments (less than 1\%). To reduce measurement problems arising from quality differences between firms and over time, we only consider those products which are measured in physical units (weight, length, area, or volume), whereas we remove all products which are measured in other units such as "items" or "pairs." 23 We further remove all products which are produced by less than six establishments in order to be able to compute a meaningful average price for each product.

We only consider those establishment-year observations where the valid products are representative in the sense that they contribute at least $50 \%$ of the total revenue of the establishment (similar to Foster et al., 2008). The final sample includes 350,129 establishment-year observations. In Appendix A.2, we present the distributions of establishments, employment, and revenue by size class and by industry. Over a third of employment and revenue is concentrated in the largest $5 \%$ of establishments with more than 500 workers, whereas a third of establishments employ less than 50 workers. ${ }^{24}$ Our data include single-establishment firms as well as establishments belonging to multiestablishment firms. Over three quarters of establishments and about $50 \%$ of employment are in single-establishment firms. The statistics that we use in the following analysis do not change much when we restrict the panel to singleestablishment firms. We thus refer to "firms" in the rest of this article, keeping in mind that our statistics are calculated at the establishment level.

3.1.1. Measuring price and productivity dynamics. Firms in our model are hit by exogenous shocks to (physical) productivity $x$ and demand $y$, both of which follow Markov processes. We parameterize them as $\mathrm{AR}(1)$ processes

$$
\begin{aligned}
& \log \left(x_{i t}\right)=\rho^{x} \log \left(x_{i, t-1}\right)+\sigma^{x} \varepsilon_{i t}^{x}, \\
& \log \left(y_{i t}\right)=\rho^{y} \log \left(y_{i, t-1}\right)+\sigma^{y} \varepsilon_{i t}^{y},
\end{aligned}
$$

where $\varepsilon_{i t}^{x}$ and $\varepsilon_{i t}^{y}$ are standard normally distributed. To inform the parameters $\rho^{x}$ and $\sigma^{x}$ for productivity dynamics, we obtain statistics for the firm dynamics of QLP (output per unit of labor) which is identical to parameter $x$ in our model. The demand state $y$ cannot be directly observed in the data (or backed out from observables), but we can make use of the close connection between prices and firm-specific demand $y$ via Equation (13). ${ }^{25}$ Therefore, we utilize information about price dynamics to estimate parameters $\rho^{y}$ and $\sigma^{y}$ via indirect inference, jointly with other internally estimated parameters as described below.

To construct measures of a firm-specific price index and QLP, we proceed as follows: Let $R_{i j t}$ and $Q_{i j t}$ be the revenue and quantity values of product $j$ in firm $i$ and year $t .{ }^{26}$ We define

\footnotetext{
${ }^{23}$ The underlying hypothesis is that products measured in physical units have a lower degree of processing, so that quality differences are less important. To give examples, our sample includes products "1720 32 144: Fabric of synthetic fibers (with more than $85 \%$ synthetic) for curtains (measured in $\mathrm{m}^{2}$ )" and "2112 30 200: Cigarette paper, not in the form of booklets, husks, or rolls less than $5 \mathrm{~cm}$ broad (measured in $t$ )", whereas it does not include " 174024 300: Sleeping bags (measured in 'items')" and "2513 60 550: Gloves made of vulcanized rubber for housework usage (measured in 'pairs')" (numeric codes based on product classification 2002).

${ }^{24}$ The average establishment in our sample is quite large: the mean (median) size is about 150 (70) employees, which is due to the fact that our sample is truncated below at 20 employees and that it covers the manufacturing sector.

${ }^{25}$ The firm's price in the model is a quantity-weighted average of prices charged on new and repeat buyers (see Appendix A.1).

${ }^{26}$ To take into account that these products may represent less than $100 \%$ of the revenue of a firm, we follow Foster et al. (2008) and scale these numbers up by the same proportionality factor to make sure that the sample revenue
} 
firm i's price of product $j$ by $P_{i j t}=R_{i j t} / Q_{i j t}$ from which we obtain a quantity-weighted average price of good $j$ in year $t$,

$$
\bar{P}_{j t} \equiv \frac{\sum_{i} P_{i j t} Q_{i j t}}{\sum_{i} Q_{i j t}}
$$

Recall that this summation is over at least six firms for any of the products that we consider. We use average product prices to measure a firm's QLP. Whereas revenue labor productivity (RLP) is obtained by dividing a firm's actual revenue by labor hours, quantity labor productivity divides the firm's output value at average market prices by labor hours:

$$
\operatorname{RLP}_{i t} \equiv \frac{\sum_{j} Q_{i j t} P_{i j t}}{H_{i t}} \quad \text { and } \quad \operatorname{QLP}_{i t} \equiv \frac{\sum_{j} Q_{i j t} \bar{P}_{j t}}{H_{i t}},
$$

where $H_{i t}$ are working hours. RLP is the product of QLP and the firm's price index $\widetilde{P}_{i t}$ :

$$
\mathrm{RLP}_{i t}=\mathrm{QLP}_{i t} \cdot \widetilde{P}_{i t} \quad \text { where } \quad \widetilde{P}_{i t} \equiv \frac{\sum_{j} P_{i j t} Q_{i j t}}{\sum \bar{P}_{j t} Q_{i j t}} .
$$

This price index expresses the firm's actual revenue relative to the hypothetical revenue had the firm sold its products at the (quantity-weighted) average market prices. ${ }^{27}$

Since we are interested in within-firm dynamics of prices and productivity, we regress $\log \mathrm{QLP}_{i t}$ and $\log \widetilde{P}_{i t}$ on firm and time fixed effects and denote the residual terms by $q_{i t}$ and $p_{i t}$, respectively. As noted above, $q_{i t}$ is the direct analog of the exogenous variable $\log x_{i t}$ in the model, so that we calibrate the autocorrelation and standard deviation parameters $\rho^{x}=0.629$ and $\sigma^{x}=0.266$ directly so as to replicate the autocorrelation (0.629) and standard deviation (0.342) of its empirical counterpart $q_{i t}$.

Prices, on the other hand, are an endogenous model outcome and depend on all firm's exogenous and endogenous state variables. Yet, their statistical properties closely follow those of the firm's demand state $y_{i t}$. Therefore, we estimate parameters $\rho^{y}$ and $\sigma^{y}$ to match the autocorrelation (0.644) and standard deviation (0.260) of the empirical price measure $p_{i t}$.

A possible concern about our measurement of prices and productivity is the role of outliers and measurement error. To deal with the former, we remove all observations where the firm's price index or QLP are below the second or above the 98th percentiles of their respective distributions. Our restriction to products measured in physical units reduces the impact that quality differences take on prices. Nonetheless, if quantities are measured with error, our data would generate a spurious negative correlation between prices and quantities. To deal with this concern, we introduce measurement error into our model, reestimate the parameters and show that our main results are similar to those of the benchmark model without measurement error (see Appendix A.3 for the results).

3.2. Parameterization. We calibrate the model at annual frequency. The first set of parameters is calibrated directly, whereas the remaining parameters are jointly estimated to match suitable data targets. We set the discount factor to $\beta=0.96$ to reflect a $4 \%$ interest rate. The firm exit rate is $\delta=0.02$, corresponding to the annual exit rate of German firms with 20 or more workers (see Fackler et al., 2013).

The exogenous worker separation rate is set to $\bar{\delta}_{w}=0.02$ so that the total separation rate in the stationary equilibrium is around $7 \% .{ }^{28}$ The exogenous customer separation rate is set

$\sum_{j} R_{i j t}$ equals the total revenue of firm $i$ in year $t$. This adjustment is a valid modification of the data presuming that the goods in our sample are sufficiently representative for the set of all goods that this firm produces.

27 This index is analogous to the construction of a household-level price index in Kaplan and Menzio (2015).

28 These targets are based on Fuchs and Weyh (2010) who measure plant-level job creation and destruction rates from the Establishment History Panel of the Institute for Employment Research (IAB) for the period 2000-2006. 
to $\bar{\delta}_{b}=0.43$; this number corresponds to the finding of Stahl (2010) that repeat customers account for $57 \%$ of the annual revenue in German manufacturing firms.

We directly set the CES parameter $\theta=0.8$ in line with markup estimates for German manufacturing sector of around 25\% (cf., Deutsche Bundesbank, 2017). The utility function has constant elasticity, $u(C)=u_{0} C^{1-\sigma} /(1-\sigma)$ with $\sigma \geq 0$. We set $\sigma=2 / 3$ so that the elasticity of industry demand corresponds to the mean estimate for U.S. manufacturing industries of Chang et al. (2009). The marginal valuation of a good in the model equals $y u^{\prime}(C)$ in units of the numeraire good. As the unit of measurement is arbitrary, we normalize the average value of $M=u^{\prime}(C) C^{1-\theta}$ to unity by setting the mean value of the demand shock to $\log (\bar{y})=0$ and adjusting the scale parameter $u_{0}$ accordingly.

For recruitment and sales costs, we adopt the cubic specifications $r(R)=r_{0} R^{3}$ and $s(S)=$ $s_{0} S^{3}$. Convex adjustment costs give rise to sluggish adjustment of employment and customers, together with variation in wage offers and discount prices. Matching functions in the labor market and in the product market are Cobb-Douglas: $m(\lambda)=m_{0} \lambda^{\mu}$ and $q(\varphi)=q_{0} \varphi^{\gamma}{ }^{29}$ The labor market matching function elasticity is directly set to a standard value of $\mu=0.5$ (e.g., Petrongolo and Pissarides, 2001). All further parameters in these cost and matching functions, namely, $\left(r_{0}, s_{0}, m_{0}, q_{0}, \gamma\right)$ are internally calibrated, together with the two parameters for the $\operatorname{AR}(1)$ process of firm-specific demand $\left(\rho^{y}, \sigma^{y}\right)$, the entry cost parameter $K$, the product market search $\operatorname{cost} \kappa$, and unemployment income $b$.

These 10 parameters are jointly estimated to match the following 10 targets : (i) The scale parameters $r_{0}$ and $s_{0}$ are identified to match plausible shares of spending on recruitment and sales; specifically we target recruitment (sales) expenditures to be $1 \%(2 \%)$ of GDP as in Christiano et al. (2016) (Arseneau and Chugh, 2007). (ii) The scale parameter $m_{0}$ of the labor market matching function is set to match a stationary unemployment rate of $8.5 \%$ which is the data average of the OECD harmonized unemployment rate over the period 1995-2014; (iii) For the two parameters $q_{0}$ and $\gamma$ of the product market matching function, we make use of the insight that the elasticity $\gamma$ is crucial for the firms' responsiveness of employment adjustments. ${ }^{30}$ Therefore, we target the standard deviation of log employment growth of $12.5 \%$. The scale parameter $q_{0}$ is set such that the average matching probability of a buyer is $50 \%$ so that every second search attempt of a retail buyer is successful. ${ }^{31}$ (iv) The entry cost $K$, through its impact on the endogenous search value $\rho$ determines average firm size. We target that the median firm in our data employs 70 workers. ${ }^{32}$ (v) The retailer search cost parameter $\kappa$, via its impact on the difference between retail and producer prices, determines profits in the retail sector. We target that the gross operating surplus (retail profits) is $5 \%$ of total sales. ${ }^{33}$ (vi) The unemployment income parameter $b$ is set to match $60 \%$ of the average wage, reflecting the unemployment replacement rate in Germany (cf., Krebs and Scheffel, 2013). (vii) The standard deviation (0.260) and annual autocorrelation (0.644) of the empirical firm-specific price index (after controlling for firm fixed effects) identifies the AR(1) parameters $\rho^{y}$ and $\sigma^{y}$. We estimate these 10 parameters via a simulated method of moments procedure where we

\footnotetext{
${ }^{29}$ For both matching functions, we make sure that matching rates of workers and shoppers $(m(\lambda) / \lambda$ and $q(\varphi) / \varphi$, respectively) do not exceed one; that is, we set $m(\lambda)=\min \left(\lambda, m_{0} \lambda^{0.5}\right)$ and $q(\varphi)=\min \left(\varphi, q_{0} \varphi^{0.5}\right)$.

${ }^{30}$ See the discussion in Subsection 2.4 for a formal argument. In our calibrated model, we verify this relationship numerically; see the results in Table 2 discussed below.

${ }^{31}$ Since no separate information on individual transactions and matching processes between retailers and producers is available, this choice is rather arbitrary. Therefore, we conduct a robustness analysis with respect to this parameter. These results and further sensitivity experiments with respect to the customer separation rate $\bar{\delta}_{b}$ and the sales expenditure target are presented in Appendix A.3.

${ }^{32}$ Note that average productivity is normalized given that the mean of $\log x$ is equal to zero. Parameter $K$ cannot be identified independently of the average values of firm productivity $x$ because firm-level value functions are linearly homogeneous in the vector $\left(x, b^{1 / \theta}, r_{0}^{1 / \theta}, s_{0}^{1 /(\theta-3)}, \rho^{1 / \theta}, \kappa^{1 /(\theta-1)}, B, S, K\right)$ (see problem $(20)$, together with the assumed functional forms), so that all firm-level policies are independent of scaling transformations.

${ }^{33}$ See Table 45341-001 (gross operating surplus in retail excluding cars) at Statistisches Bundesamt (www.destatis. de).
} 
TABLE 1

PARAMETER VALUES AND CALIBRATION TARGETS

\begin{tabular}{|c|c|c|c|c|}
\hline \multicolumn{5}{|c|}{ Directly Calibrated Parameters } \\
\hline Parameter & & Value & \multicolumn{2}{|c|}{ Explanation/Target } \\
\hline$\beta$ & & 0.96 & \multicolumn{2}{|c|}{ Annual interest rate $4 \%$} \\
\hline$\delta$ & & 0.02 & \multicolumn{2}{|c|}{ Firm exit rate (Fackler et al., 2013) } \\
\hline $\bar{\delta}_{w}$ & & 0.02 & \multicolumn{2}{|c|}{ Worker separation rate $7 \%$} \\
\hline $\bar{\delta}_{b}$ & & 0.43 & \multicolumn{2}{|c|}{ Customer retention rate $57 \%$} \\
\hline$\theta$ & & 0.8 & \multicolumn{2}{|l|}{ Markup 25\% } \\
\hline$\sigma$ & & 0.666 & \multicolumn{2}{|c|}{ Price elasticity of industry demand -1.5} \\
\hline$\rho^{x}$ & & 0.629 & \multicolumn{2}{|c|}{ Autocorrelation of $\log$ QLP } \\
\hline$\sigma^{x}$ & & 0.266 & \multicolumn{2}{|c|}{ Standard deviation of log QLP } \\
\hline \multicolumn{5}{|c|}{ Internally Calibrated Parameters } \\
\hline Parameter & Value & & Target & Model \\
\hline$r_{0}$ & $3.16 \cdot 10^{-5}$ & & Recruitment costs ( $1 \%$ of output) & $1.27 \%$ \\
\hline$s_{0}$ & $1.95 \cdot 10^{-3}$ & & Sales costs ( $2 \%$ of output) & $2.19 \%$ \\
\hline$m_{0}$ & 0.271 & & Unemployment rate $(8.5 \%)$ & $9.1 \%$ \\
\hline$q_{0}$ & 2.182 & & Customer matching rate $(50 \%)$ & $50.3 \%$ \\
\hline$\gamma$ & 0.362 & & Std. dev. employment growth (0.125) & 0.129 \\
\hline$b$ & 0.186 & & Unemployment income ( $60 \%$ of av. wage) & $60.7 \%$ \\
\hline$\kappa$ & 0.0196 & & GOS in retail ( $5 \%$ of sales) & $4.97 \%$ \\
\hline$K$ & 135.98 & & Average firm size (70) & 71.3 \\
\hline$\rho^{y}$ & 0.703 & & Autocorrelation of log price $(0.644)$ & 0.575 \\
\hline$\sigma^{y}$ & 0.170 & & Standard deviation of log price $(0.260)$ & 0.237 \\
\hline
\end{tabular}

minimize the unweighted squared percentage distance between the empirical and the modelimplied moments. All our parameter choices and targets are summarized in Table 1.

3.3. Implications of Product Market Frictions. PMFs are an essential feature of our model to generate plausible dynamics of employment, triggered by productivity and demand shocks which are calibrated in line with the empirical features of firm-level productivity and price changes. To see this, we compare various statistics of firm dynamics of our model with those of an alternative version of our model in which PMFs are absent. In this alternative model, there are no search costs in product markets, that is, we set $\kappa=s_{0}=0$, so that retail prices and producer prices coincide. To keep the comparison with the benchmark model as close as possible, we leave the parameters governing productivity and demand shocks unchanged and only recalibrate three model parameters to match average firm size, the unemployment rate, and the unemployment replacement rate. ${ }^{34}$ As an alternative comparison, we also recalibrate the model without PMFs from an agnostic standpoint, assuming that separate information on prices and quantities is not available so that we feed our model only with standard productivity shocks (i.e., an $\operatorname{AR}(1)$ process for $\log (x)$ while $y$ is constant). ${ }^{35}$

Table 2 compares statistical features of firm dynamics in the data and in our model with and without PMF. We look at the cross-sectional standard deviations and correlations of firm-level growth rates of prices $(\hat{p})$, physical productivity $(\hat{q})$, employment $(\hat{e})$, and output $(\hat{q})$. The first two rows of the table show that the benchmark model roughly replicates the standard deviations of price and productivity growth.

Regarding the cross-sectional dispersion of employment growth, the model with PMFs matches the data counterpart. This is implied by our calibration which identifies the product

\footnotetext{
34 This requires setting the entry cost to $K=158.7$, the matching function scale $m_{0}=0.601$, and unemployment income $b=0.237$.

${ }^{35}$ For this model, we estimate $K=109.7, b=0.206, m_{0}=0.270, r_{0}=3.96 \cdot 10^{-5}, \sigma^{x}=0.178$, and $\rho^{x}=0.740$ to match firm size $(70)$, replacement rate $(60 \%)$, unemployment rate $(8.5 \%)$, recruitment cost $(1 \%$ of output), standard deviation of employment growth (12.5\%), and autocorrelation of RLP (0.611).
} 
TABLE 2

FIRM DYNAMICS WITH AND WITHOUT PRODUCT MARKET FRICTIONS

\begin{tabular}{|c|c|c|c|c|c|c|}
\hline & Data & $\begin{array}{c}\text { PMF } \\
\text { (Benchmark) }\end{array}$ & $\begin{array}{c}\text { PMF } \\
(\gamma=0.2)\end{array}$ & $\begin{array}{c}\text { PMF } \\
(\gamma=0.6)\end{array}$ & $\begin{array}{c}\text { No PMF } \\
\text { (Both Shocks) }\end{array}$ & $\begin{array}{c}\text { No PMF } \\
\text { ( } x \text { Shocks) }\end{array}$ \\
\hline$\sigma(\hat{p})$ & 0.210 & 0.199 & 0.192 & 0.211 & 0.184 & 0.060 \\
\hline$\sigma(\hat{q})$ & 0.281 & 0.334 & 0.336 & 0.334 & 0.303 & 0.224 \\
\hline$\sigma(\hat{e})$ & 0.126 & 0.129 & 0.111 & 0.159 & 0.451 & 0.119 \\
\hline$\sigma(\hat{y})$ & 0.289 & 0.393 & 0.379 & 0.415 & 0.668 & 0.298 \\
\hline$\rho(\hat{q}, \hat{e})$ & -0.122 & 0.298 & 0.256 & 0.334 & 0.553 & 0.457 \\
\hline$\rho(\hat{y}, \hat{e})$ & 0.227 & 0.583 & 0.518 & 0.652 & 0.926 & 0.743 \\
\hline$\rho(\hat{p}, \hat{q})$ & -0.644 & -0.537 & -0.471 & -0.584 & -0.670 & -0.935 \\
\hline$\rho(\hat{p}, \hat{e})$ & 0.003 & 0.064 & 0.099 & 0.011 & -0.252 & -0.743 \\
\hline$\rho(\hat{p}, \hat{y})$ & -0.638 & -0.436 & -0.388 & -0.466 & -0.474 & -1.000 \\
\hline $\mathrm{JC}$ rate $(\%)$ & 2.9 & 3.8 & 3.2 & 4.4 & 14.8 & 3.2 \\
\hline JD rate $(\%)$ & 3.0 & 2.4 & 1.9 & 2.9 & 10.4 & 1.8 \\
\hline
\end{tabular}

Notes: $\hat{p}, \hat{q}, \hat{e}$, and $\hat{y}$ denote annual log growth rates of prices, physical productivity, employment, and output, $\sigma($. and $\rho($.$) are cross-sectional standard deviations and correlation coefficients. Data statistics are based on the firm-$ specific price index and quantity labor productivity as defined in Subsection 3.1.

Source: Research Data Centers of the Federal Statistical Office and Statistical Offices of the Länder, panel Industriebetriebe and module Produkte, survey years 1995-2014, and own calculations.

market matching function elasticity (parameter $\gamma$ ) by this data target. In fact, this elasticity determines how tightly firms are demand constrained and hence how quickly they are able to adjust employment in response to shocks. To demonstrate the role of this parameter, columns 3 and 4 show the model outcomes if parameter $\gamma$ is either set to a lower $(\gamma=0.2)$ or a higher value $(\gamma=0.6)$, whereas all other parameters are reestimated based on the same data targets. It can be seen that the standard deviation of employment growth and job flow rates are either too low (for $\gamma=0.2$ ) or too high (for $\gamma=0.6$ ) compared to the benchmark model and the data. Hence, and in line with our discussion in Subsection 2.4, firms are more demand constrained when the product market search externality on the side of sellers is large ( $\gamma$ is low) so that employment is less responsive to productivity shocks.

In contrast, the model without PMFs in which firms face the same shock processes for productivity and demand (column 5) generates too large dispersion of employment growth. In this model, adjustment costs only arise from labor market frictions, whose underlying parameters are pinned down by labor market targets (recruitment costs, separation, and matching rates). PMFs introduce additional adjustment costs which enables our model to replicate plausible firm-level variability of productivity, prices, and employment.

If separate price and output information were not available, a researcher might want to use the model without PMFs with only one type of shock (here, as in most standard models, an $\mathrm{AR}(1)$ process for logged productivity $x$ ) in order to match the standard deviation of employment growth. The last column of Table 2 shows the outcome of this exercise (see footnote 35 for parameter values and calibration targets). Different from the calibration in column 5 , this model is forced to match the empirical standard deviation of employment growth. In turn, the implied volatilities of prices and QLP are then far too low. We return to this model when we discuss the impact of aggregate shocks in Subsection 3.5.

The dampening of employment adjustments arising from PMFs can also be seen in the bottom two rows of the table which reports job creation and destruction rates. ${ }^{36}$ Although the benchmark model somewhat overpredicts (underpredicts) the magnitude of job creation (job destruction) for continuing firms, both job flow rates are much too high in the model without PMFs and both types of shocks (column 5).

\footnotetext{
${ }^{36}$ Both in the data and in the model, we measure job creation and job destruction rates in the usual way: the job creation and destruction rates are $j c_{i t}=2 \max \left(E_{i t}-E_{i, t-1}, 0\right) /\left(E_{i t}+E_{i, t-1}\right)$ and $j d_{i t}=2 \max \left(E_{i, t-1}-E_{i, t}, 0\right) /\left(E_{i t}+\right.$ $\left.E_{i, t-1}\right)$ where $E_{i t}\left(E_{i, t-1}\right)$ is year- $t(t-1)$ employment at firm $i$. As in the data, the model sample is based on firms with 20 or more workers in both periods (hence it covers continuing firms only).
} 
(a) Output

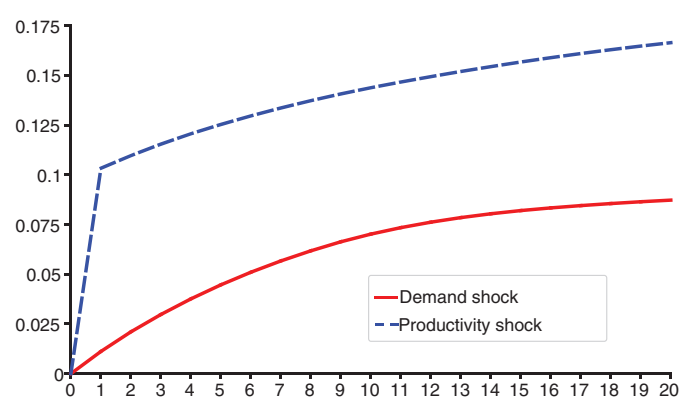

(b) Price

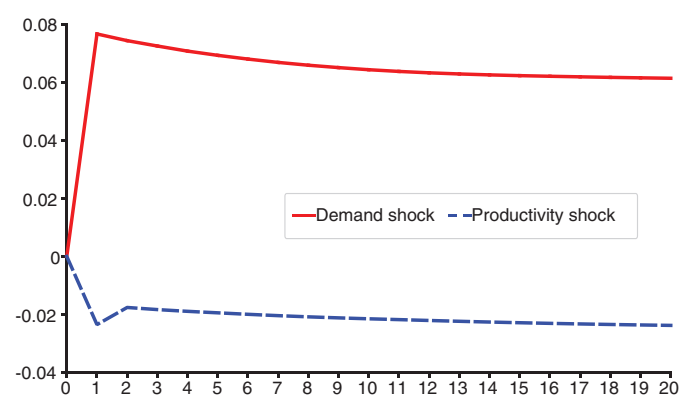

(c) Employment

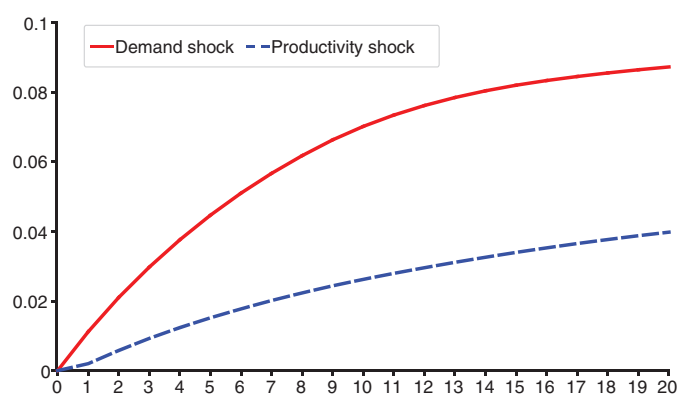

Notes: Output, price, and employment response of a firm with average demand and productivity at its steady-state size in period zero which experiences a one-time permanent increase in productivity (blue, dashed) or demand (red, solid) by $10 \%$ in period one.

FIGURE 2

OUTPUT AND PRICE RESPONSES TO FIRM-LEVEL SHOCKS [COLOR FIGURE CAN BE VIEWED AT WILEYONLINELIBRARY.COM]

Further important differences can be observed regarding the comovement of employment, output, and QLP. In the data, these cross-sectional correlations are rather modest (the one between productivity and employment is even negative), whereas the model without PMFs produces too strong positive correlations between employment, output, and QLP. These comovements are much weaker once PMFs come into play. When it is costly to adjust the customer base, firms are more reluctant to change employment in response to productivity changes.

3.4. The Role of Productivity and Demand for Firm Dynamics. To illustrate the separate roles of productivity and demand for firm dynamics, Figure 2 shows the responses of output, price, and employment to a permanent $10 \%$ increase in either demand or productivity in period one. Higher demand (an increase of the taste parameter $y$ ) allows the firm to increase its price on impact for both its existing customers and for new customers. Over time, the firm expands employment and production so that it reduces the output price to sell the additional output to more customers. A positive productivity shock allows the firm to produce more output on impact. To sell the additional output, the firm cuts the discount price to attract new customers, and it also lowers the price for existing customers whose marginal valuation of the good decreases. Over time, from period two onward, the more productive firm starts to hire more workers and to attract more customers: output increases and the price declines further.

Figure 2(c) shows that a demand shock induces a stronger adjustment of employment than a productivity shock of the same relative size. This is in contrast to the model without PMFs, where an increase of $x$ or $y$ of the same size induces exactly the same response of employment. However, productivity shocks are more volatile in our calibrated model: the standard 
TABLE 3

FIRM DYNAMICS: PRODUCTIVITY AND DEMAND SHOCKS

\begin{tabular}{|c|c|c|c|c|}
\hline & Data & Both Shocks & Only $x$ Shocks & Only y Shocks \\
\hline$\sigma(\hat{p})$ & 0.210 & 0.199 & 0.106 & 0.167 \\
\hline$\sigma(\hat{q})$ & 0.281 & 0.334 & 0.336 & 0.000 \\
\hline$\sigma(\hat{e})$ & 0.126 & 0.129 & 0.098 & 0.078 \\
\hline$\sigma(\hat{y})$ & 0.289 & 0.393 & 0.385 & 0.078 \\
\hline$\rho(\hat{q}, \hat{e})$ & -0.122 & 0.298 & 0.390 & 0.000 \\
\hline$\rho(\hat{y}, \hat{e})$ & 0.227 & 0.583 & 0.595 & 1.000 \\
\hline$\rho(\hat{p}, \hat{q})$ & -0.644 & -0.537 & -0.969 & 0.000 \\
\hline$\rho(\hat{p}, \hat{e})$ & 0.003 & 0.064 & -0.465 & 0.327 \\
\hline$\rho(\hat{p}, \hat{y})$ & -0.638 & -0.436 & -0.964 & 0.327 \\
\hline $\mathrm{JC}$ rate $(\%)$ & 2.9 & 3.8 & 2.7 & 2.5 \\
\hline JD rate $(\%)$ & 3.0 & 2.4 & 1.4 & 1.1 \\
\hline
\end{tabular}

Notes: See the notes of Table 2 for explanations.

deviation of innovations to $x$ (0.266) exceeds the one for innovations to $y(0.170)$. Hence, it is a priori unclear how much these two forces matter for the firms' labor market adjustments.

To assess the separate roles of demand and productivity for firm dynamics, we report in Table 3 selected statistics for the benchmark model if either demand shocks or productivity shocks are absent. Both types of shocks contribute significantly to employment adjustments. In the absence of demand shocks ("Only $x$ Shocks"), the model generates somewhat higher employment volatility, compared to the scenario where productivity shocks are absent. Also, productivity shocks account for a slightly larger share of job flows than demand shocks: Job destruction at continuing firms would fall by more than $50 \%(40 \%)$ if productivity (demand) shocks were absent. The unemployment rate would fall by more than 3 percentage points in the absence of either one of the two forces.

Productivity shocks are considerably more relevant for output dynamics, whereas demand shocks contribute more to price volatility. The fact that our model reproduces the negative empirical comovement between firm-level prices and output (an untargeted moment), and a negative comovement between prices and productivity, is obviously induced by the presence of productivity shocks. The zero correlation between price and employment growth, both in the data and in the benchmark model, is explained by the offsetting forces of both shocks. If only one of the two shocks was active, price and employment growth would either be positively or negatively correlated, and price and output growth would either be perfectly negatively or positively correlated. And if productivity shocks were absent, employment and output growth would be perfectly correlated. Taking all these findings together, Table 3 highlights that both productivity and demand shocks, and their interplay with PMFs as implied by Table 2 , are necessary features to capture the joint dynamics of prices, productivity, and employment across firms.

3.5. Aggregate Dynamics. How does the model economy respond to aggregate shocks to the first or second moment of either productivity or demand? We are interested in the cyclical features of macroeconomic aggregates (i.e., output, employment, and prices) as well as crosssectional dynamics, in particular the dispersions of price and output growth across firms. To this end, we first look at the cyclicality of firm dispersion measures in our data. Then we analyze the impulse responses of different types of shocks in the model.

The literature documents countercyclical firm dispersion, based on the cross-sectional standard deviation of firms' revenue growth and other dispersion measures (e.g., Bloom et al., 2018). Our data allow us not only to confirm these findings for the manufacturing sector in Germany but also to document the separate cyclicalities of price and output growth 
(a) Means

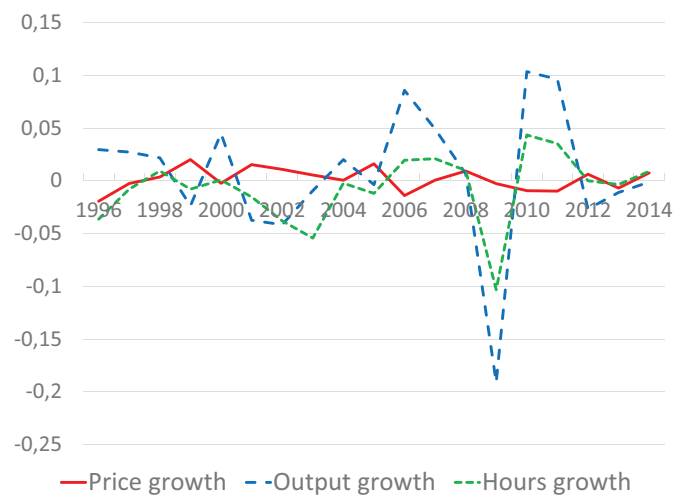

(b) Standard deviations

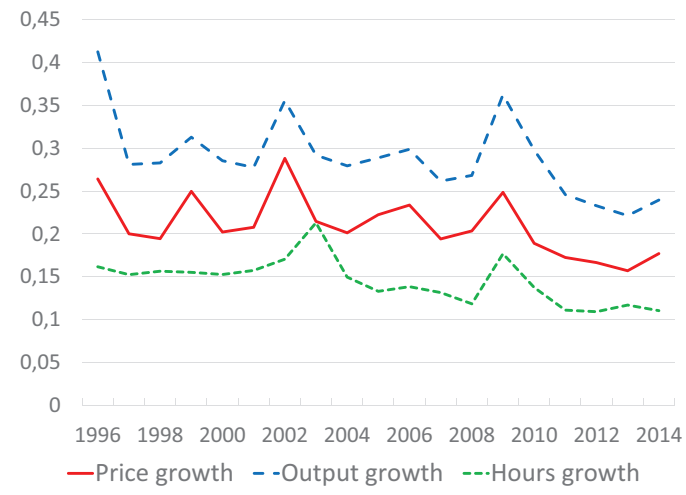

DATA SOURCE: Research Data Centers of the Federal Statistical Office and Statistical Offices of the Länder, panel Industriebetriebe and module Produkte, survey years 1995-2014, own calculations.

FIGURE 3

MEANS AND STANDARD DEVIATIONS OF PRICE, OUTPUT, AND HOURS GROWTH RATES (1996-2014)
[COLOR FIGURE CAN BE VIEWED AT WILEYONLINELIBRARY.COM]

dispersion. ${ }^{37}$ We find that both standard deviations of output growth and price growth are countercyclical. Since $\log$ revenue growth is the sum of log price growth and $\log$ output growth, both price and output growth dispersion contribute to the countercyclicality of revenue growth dispersion.

Figure 3 shows time series of the cross-sectional means and standard deviations of price growth, output growth, and hours growth. Germany had two recessions in the sample period (2002/2003 and 2009). In both recessions, unsurprisingly, the means of output and hours growth go down. ${ }^{38}$ Moreover, during the 2002/2003 recession and the subsequent recovery, output growth leads hours growth. As shown in the right panel of Figure 3, all three dispersion measures go up in both recessions, albeit by different magnitudes, and again hours growth dispersion is lagging behind in the 2002/2003 recession. Over the reported 19-year period, the means of the output and hours growth are procyclical, whereas standard deviations of all three series are countercyclical. ${ }^{39}$

To see how macroeconomic variables and firm-level dispersion measures react to aggregate shocks, we compare the impulse responses of our model economy to four types of aggregate events: (i) a decrease in either mean productivity $\bar{x}$ or mean demand $\bar{y}$ by $5 \%$; (ii) an increase in the standard deviation of shocks to firm productivity $x$ or firm demand $y$ by $20 \%$ (productivity or demand uncertainty shock).$^{40}$ In all four experiments, we let the initial shock decline with annual autocorrelation 0.7 and consider the adjustment path back to the original steady state.

Despite the characterization of the stationary equilibrium by a joint-surplus maximization problem, the aggregate dynamics has no block-recursive solution, in contrast to other

\footnotetext{
${ }^{37}$ See also Bachmann and Bayer (2014) who document countercyclical dispersion of firm-level growth rates of employment, value added, and factor productivity for Germany during the period 1973-98. Berger and Vavra (2018) find countercyclical price growth dispersion in the U.S. data.

${ }^{38}$ We use hours instead of employment here because the labor market reforms in Germany during the 2000s (Hartz I-IV) have decisively altered the employment dynamics in Germany. In particular, aggregate employment barely fell during the Great Recession (cf., Burda and Hunt, 2011).

39 The correlations with (linearly) detrended value added in manufacturing are $(0.035,0.743,0.789)$ for the means of (price, output, hours) growth and $(-0.372,-0.514,-0.504)$ for the standard deviations of (price, output, hours) growth.

${ }^{40}$ Because AR(1) processes for the idiosyncratic states are expressed in the logs of $x$ and $y$, we rescale the levels so that the means of $x$ and $y$ stay the same when the standard deviation of shocks increases.
} 
competitive-search models. The reason is that marginal utility of aggregate consumption responds to changes in the distribution of firms which in turn feeds back into the firms' problem. Therefore, we need to loop over the transition path of aggregate consumption $C_{t}$ together with workers' search values $\rho_{t}$ to solve for the transition path. ${ }^{41}$

Figure 4 shows the economy's response to negative mean productivity and demand shocks. The negative productivity shock generates a $5 \%$ decline of output on impact whereas employment shows a tiny increase on impact (about $0.1 \%$ ) which is a result of a substantial drop of the workers' search value $\rho_{t}$ in response to the shock which reduces wages and which makes it (slightly) more attractive for incumbent firms to hire. Potential entrants, however, find it less profitable to enter so that the number of firms falls over time, resulting in a long-term decline in aggregate employment, which is however relatively small (about $-0.25 \%$ ). Panel (c) shows that firms pass on the higher labor costs to customers: prices increase on impact by almost $4 \%$.

The response to a negative demand shock is rather different. Again, entry falls and wages drop in response to the reduction in firm revenue and the declines of output and employment by $0.3(0.25)$ are rather modest. Firms cut prices to accommodate customers' lower valuations of their products.

The bottom two graphs in Figure 4 show the responses of price and output growth dispersion to the two shocks. Negative productivity and demand shocks raise the dispersion of output growth and reduce the dispersion of price growth, with larger responses for declining productivity. Intuitively, both shocks reduce the level of aggregate production, whereas the magnitude of idiosyncratic uncertainty and adjustment costs stay the same. As growth rates are expressed in percentage terms, the dispersion of output growth rises whereas the dispersion of price growth falls. In both cases, however, the magnitudes are rather small.

We conclude that aggregate shocks to the first moments of productivity or demand do not generate the countercyclical dispersion of price growth that we observe in the data and they only lead to a small increase of output growth dispersion. Moreover, both shocks only generate modest declines of economic activity. The latter finding is a consequence of our calibration strategy which sets the flow income during unemployment (parameter $b$ ) equal to a plausible value of unemployment benefits in relation to wages. As a result, the surplus value of a job is relatively large which in turn implies that movements in productivity (likewise, in aggregate demand) cannot have large effects on the labor market (see, e.g., Ljungqvist and Sargent, 2017). In contrast, if we calibrate $b$ to a much higher value, for instance reflecting the value of leisure, our model can produce considerably more amplification (cf., Hagedorn and Manovskii, 2008). What is more, and different from our benchmark calibration, negative firstmoment shocks to productivity or demand can induce (small) increases of price and output growth dispersion. See Appendix A.3 for the details.

Quite different is the reaction of our model economy to uncertainty shocks, as we illustrate in Figure 5. In particular, the demand uncertainty shock generates declines in output and employment which are more sizable than the shocks to the first moment of demand considered above. Furthermore, the two reported measures of firm dispersion rise in response to greater demand uncertainty (panels (e) and (f)).

An increase in productivity uncertainty, in contrast, generates a positive response of output (while employment drops). On the other hand, given that firms' output growth is strongly driven by productivity shocks (cf., Figure 2), greater productivity uncertainty triggers a large increase in the standard deviation of output growth (panel (e)). The explanation for the differential effect of the two uncertainty shocks on aggregate output comes from the asymmetric impact on firms experiencing high and low realizations of these idiosyncratic shocks. Specifically, a firm's output response to positive productivity shocks is on impact much larger than

\footnotetext{
${ }^{41}$ Our model in Section 2 is described in steady state without aggregate risk. To incorporate the latter, we are assuming here that the firms' wage contracts are contingent on the aggregate state of the economy. In response to aggregate events, contractual wages and separation rates adjust, which ensures that the response of the competitive-search equilibrium to these shocks is identical to the solution of simplified joint-surplus maximization problem that we consider.
} 
(a) Output

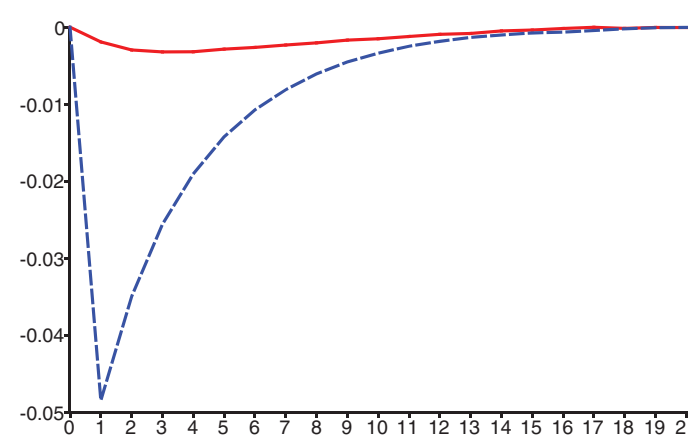

(c) Price

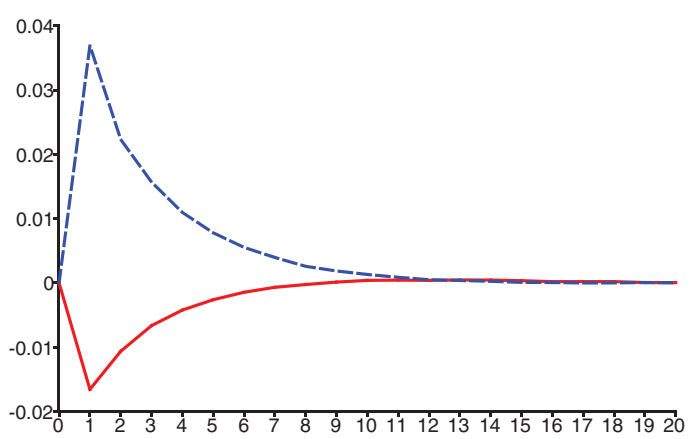

(e) Standard deviation of output growth

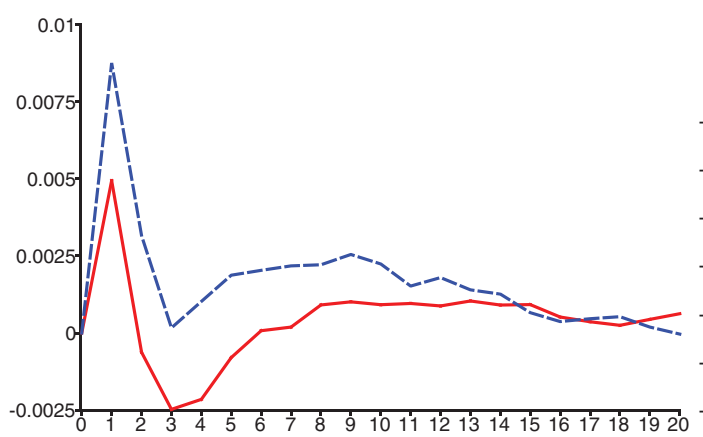

(b) Employment

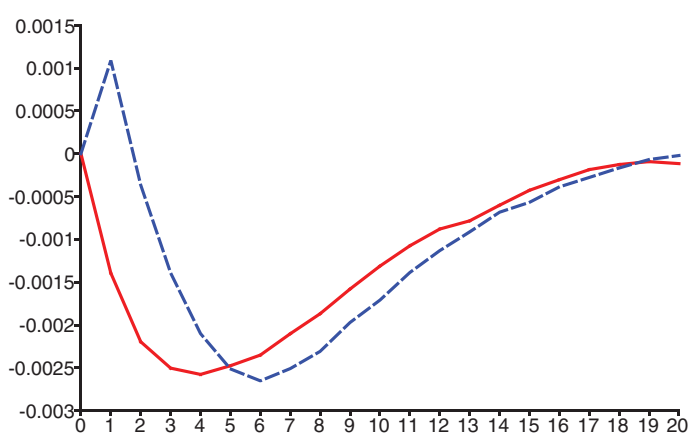

(d) Firms

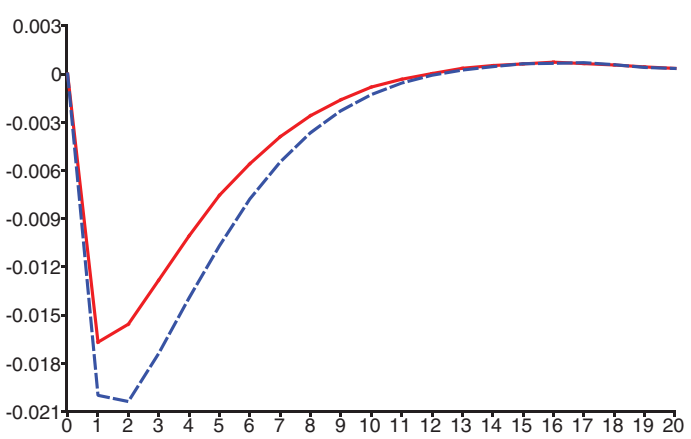

(f) Standard deviation of price growth

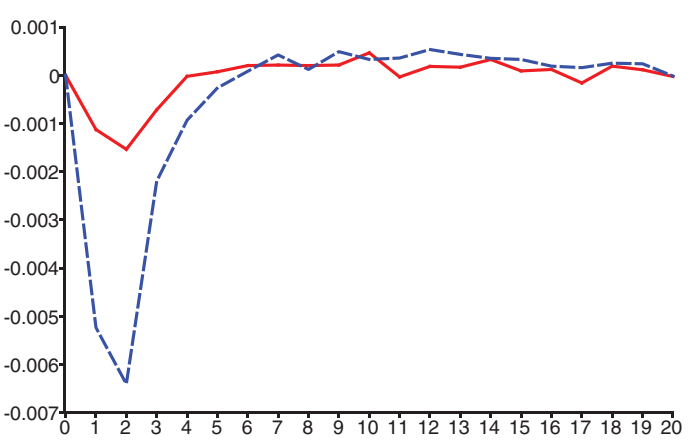

FIGURE 4

RESPONSES TO A 5\% DECREASE OF AGgREgATE PRODUCTIVITY (DASHED, BLUE) AND AGGREGATE DEMAND (SOLID, RED) [COLOR FIGURE CAN BE VIEWED AT WILEYONLINELIBRARY.COM]

the one to a demand shock of the same relative magnitude (see again Figure 2), whereas the output cuts in response to negative shocks are smaller and more aligned.

Based on these findings, we conclude that higher demand uncertainty is a plausible feature of recessions: it can induce declines in output and employment together with increasing dispersion of price and output growth. On the other hand, aggregate shocks to productivity, either to the first or to the second moment, do not deliver meaningful impulse responses in our model.

By way of comparison, the model without PMFs which is fed with productivity shocks only (see Subsection 3.3 and the last column of Table 2) does not generate a recessionary reaction to an increase in uncertainty. This is shown by the short-dashed (red) impulse responses in 
(a) Output

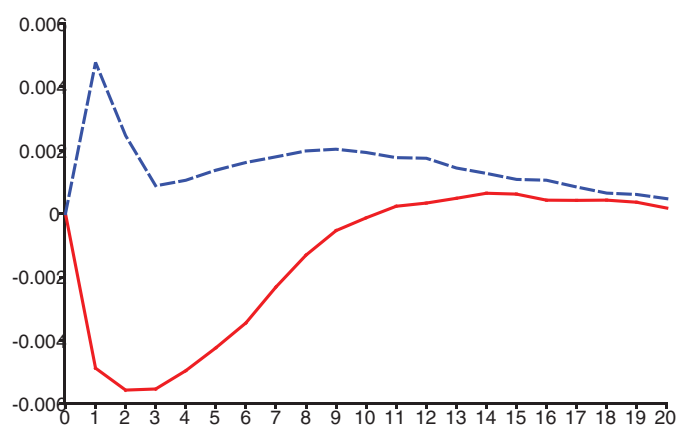

(c) Price

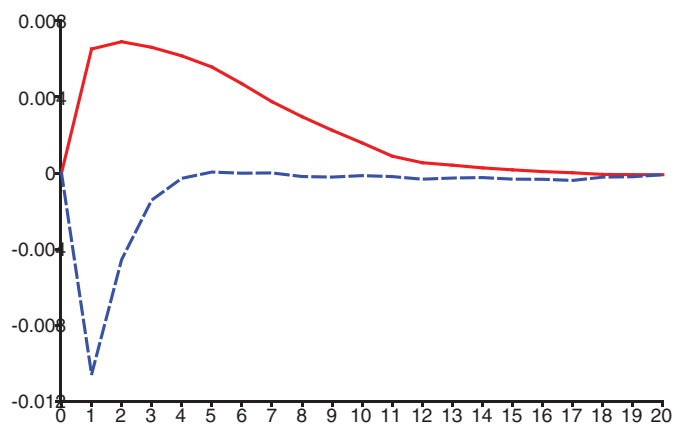

(e) Standard deviation of output growth

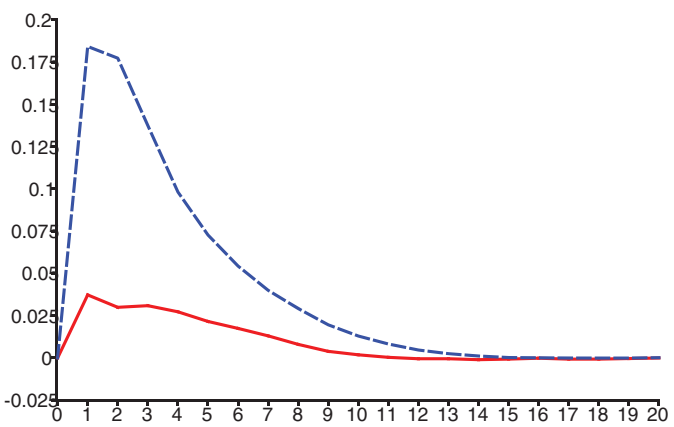

(b) Employment

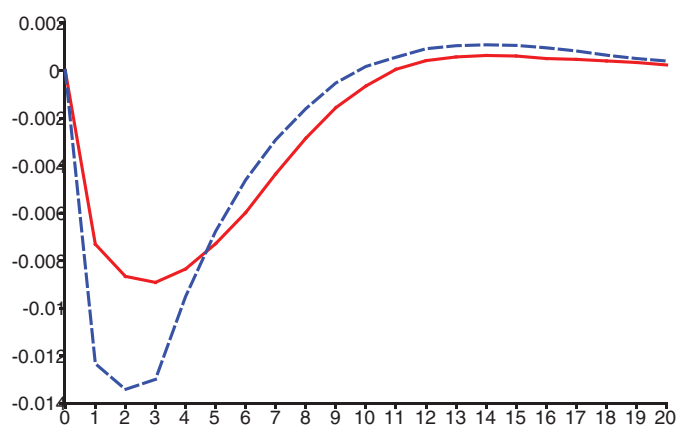

(d) Firms

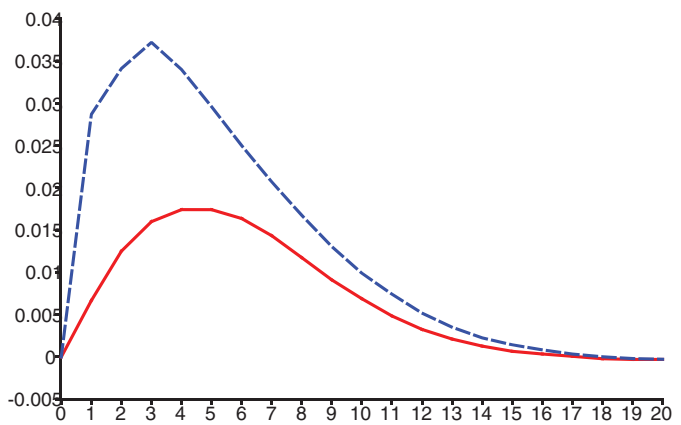

(f) Standard deviation of price growth

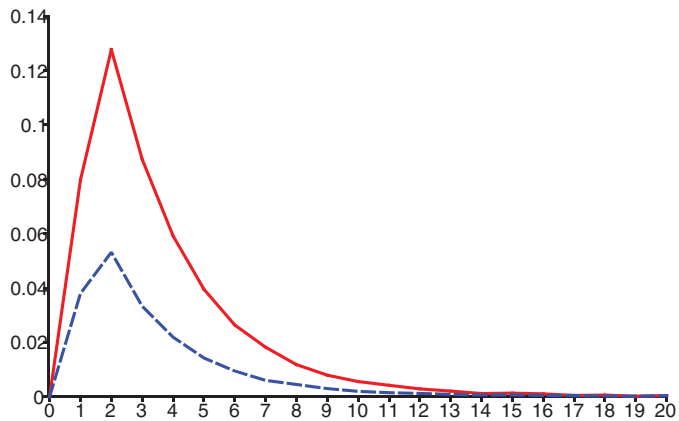

FIGURE 5

RESPONSES TO AN INCREASE OF AGGREGATE PRODUCTIVITY UNCERTAINTY (DASHED, BLUE) AND AGGREGATE DEMAND UNCERTAINTY (SOLID, RED) [COLOR FIGURE CAN BE VIEWED AT WILEYONLINELIBRARY.COM]

Figure 6: in response to the $20 \%$ impact increase of productivity uncertainty (triggering isomorphic increases in output and price growth), output increases modestly whereas employment declines. ${ }^{42}$ On the other hand, a negative shock to aggregate productivity induces a sluggish and mild reduction of employment, but it does not increase the standard deviations of output or price growth (see the dashed, blue impulse responses).

42 The literature cited in the introduction is inconclusive regarding the impact of pure uncertainty shocks on output. In different economic environments, in particular regarding the modeling of adjustment costs, Bachmann and Bayer (2014) and Schaal (2017) find negligible output responses, whereas Bloom et al. (2018) observe a sizable drop of aggregate output to a pure uncertainty shock. 
(a) Output

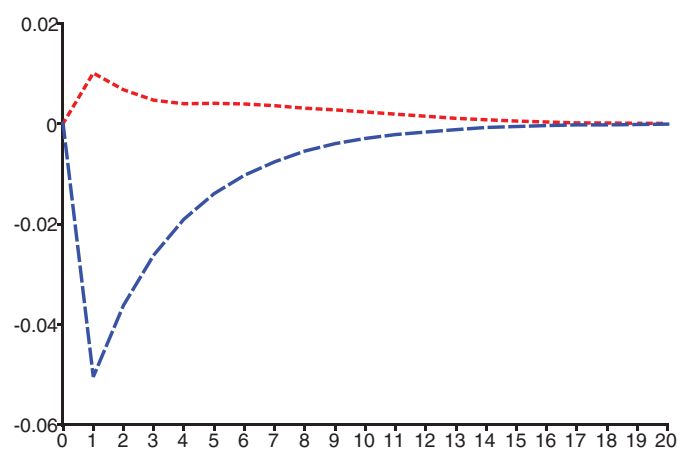

(c) Price

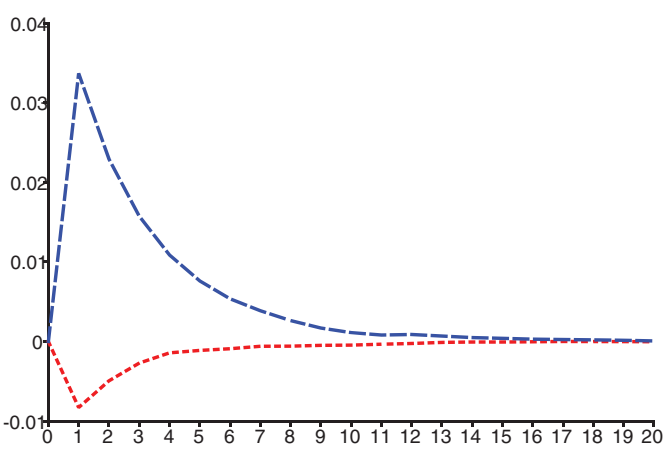

(e) Standard deviation of output growth

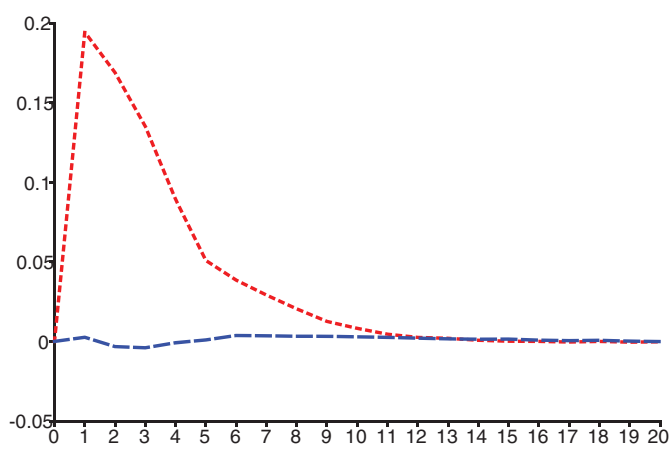

(b) Employment

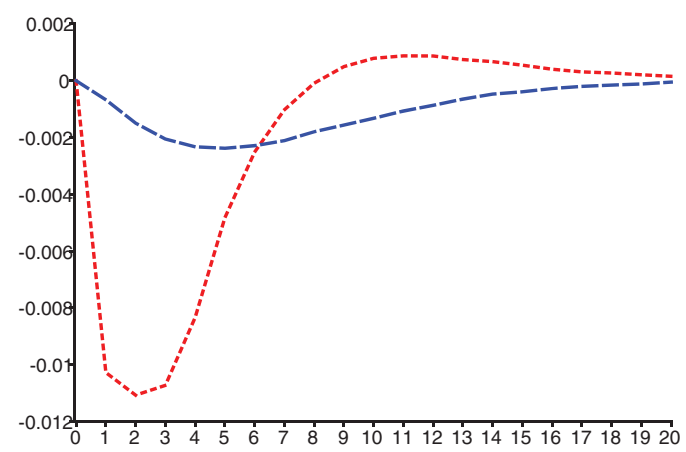

(d) Firms

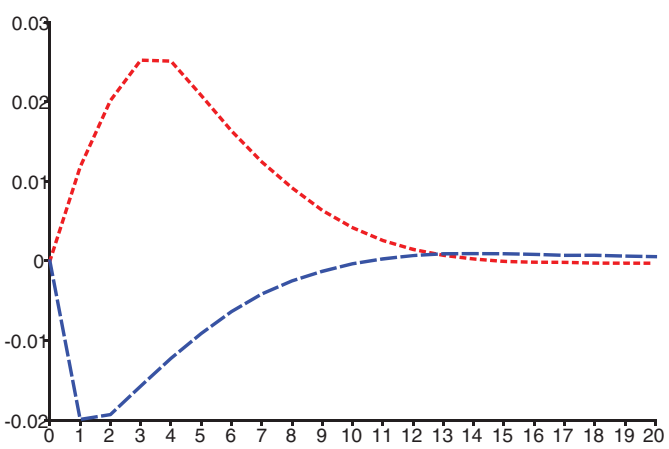

(f) Standard deviation of price growth

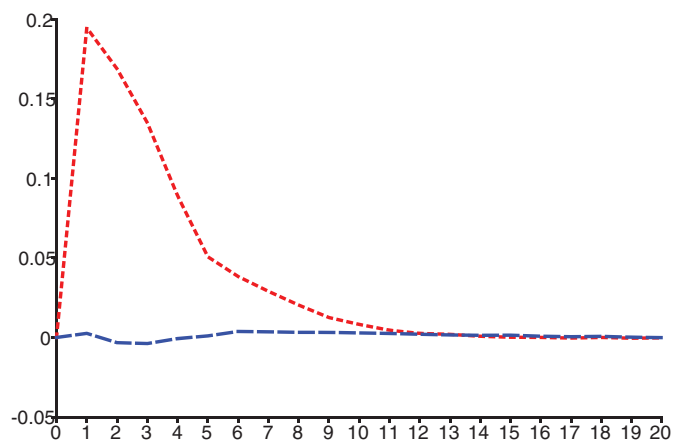

FIGURE 6

RESPONSES TO A 5\% DECREASE OF AGGREGATE PRODUCTIVITY (DASHED, BLUE) AND AGGREGATE UNCERTAINTY (SHORT DASHES, RED) IN THE MODEL WITHOUT PRODUCT MARKET FRICTIONS [COLOR FIGURE CAN BE VIEWED AT WILEYONLINELIBRARY.COM]

\section{CONCLUSIONS}

We introduce a model of heterogeneous firms which produce differentiated products and operate in frictional product and labor markets with convex sales and recruitment costs. Search frictions in the product market imply that firms are demand constrained, and hence must expend resources to spur demand. Likewise, frictions in the labor market make firms' adjustment to shocks sluggish, with consequences for the cross-sectional dynamics as well as for the aggregate economy. 
We distinguish between firm-level productivity and demand shocks which affect the firms' output and pricing policies in different ways. The extent of PMFs crucially determines how quickly firms are able to adjust employment in response to the shocks. The parameters of the shock processes are calibrated in order to match features of price and productivity dynamics of a panel of German manufacturing firms. We show that both demand and productivity shocks are necessary to describe the joint dynamics of prices, output, and employment in our data.

By means of impulse response analyses, we highlight the importance of demand uncertainty for the business cycle. Considered in isolation, declines in the mean levels of either aggregate demand or aggregate productivity cannot generate plausible recessions in the model economy with countercyclical movements of firm growth dispersion as observed in our data. By contrast, demand uncertainty shocks can induce declines of output and employment together with rising output and price growth dispersion.

In sum, our work shows how product market conditions interact with labor market conditions to generate empirically plausible firm dynamics in a fairly tractable model framework. Due to our assumption of a representative household, some important product-labor market linkages that operate through the household sector, such as the different shopping behavior of unemployed workers (Krueger and Mueller, 2010; Kaplan and Menzio, 2016), are absent from our model. Other interesting features absent from this model are direct customer turnover ("search on the shop") or an intensive demand margin. Introducing such features might have important implications for aggregate dynamics and should be an interesting avenue for further research.

\section{APPENDIX A}

\section{A.1 Proofs and Derivations.}

A.1.1 Proof of Proposition 1. Consider $\left(\rho, G, N_{0}, C\right)$ where $G$ solves the recursive jointsurplus maximization problem (20) together with (21). Furthermore, aggregate consumption is (17) and the aggregate resource constraint (19) is satisfied when $L\left(z^{a}\right), B\left(z^{a}\right)$, etc., are defined by the policy functions of problem (20). The proof proceeds in three steps. First, we construct candidate employment contracts and firm policies that resemble the joint surplus maximal solution. Second, we show that the extended policies maximize the joint surplus of a firm with commitment to previous contracts. Third, we show that the candidate policies also solve the private firm profit maximization problem and hence correspond to a competitivesearch equilibrium.

First, define candidate equilibrium contracts $\mathcal{C}^{a *}=\left(w^{a *}\left(z^{k}\right), \delta_{w}^{a *}\left(z^{k+1}\right)_{k \geq a}\right.$ with separation rates $\delta_{w}^{a *}\left(z^{k}\right) \equiv \delta_{w}\left(z^{k}\right)$ from the policy functions of problem (20) (hence, separations are independent of the tenure in the firm). Candidate equilibrium wages $w\left(z^{k}\right)$ can be defined in different ways: for instance, all workers may be paid flat wages over time, or all workers within the firm earn the same (equal treatment); see the corresponding equations at the end of this Appendix. We use equal-treatment wages for the remainder of this proof and hence specify candidate equilibrium wage contracts as $w^{a *}\left(z^{k}\right)=w\left(z^{k}\right)$, where $w\left(z^{k}\right)$ is defined as in (A4). As in Subsection 2.2.3, define the generic state vector of the firm as $\sigma=\left[\left(L^{\tau}, \mathcal{C}^{\tau}\right)_{\tau=0}^{a-1}, B_{-}, z^{a}\right]$.

Second, let $G_{a}(\sigma)$ denote the joint surplus value of a firm, assuming that the firm takes as given previous worker cohorts $L^{\tau}$ and the precommitted separation rates as specified in contracts $\mathcal{C}^{\tau}, \tau<a$. For the contracts $\left(\mathcal{C}^{\tau *}\right)_{\tau=0}^{a-1}$ in the candidate equilibrium (and the corresponding worker cohorts $L^{\tau *}$ ), write $\sigma^{*}$ for the firm's state vector. We show that these contracts, together with the other joint-surplus maximizing firm policies, indeed solve the recursive jointsurplus maximization problem with commitment. The recursive problem to maximize the joint 
surplus (for firm owners, workers, and buyers) is

$$
\begin{aligned}
G_{a}(\sigma)=\max _{\left(\lambda, R, \mathcal{C}^{a}\right),\left(\varphi, S, \delta_{b}\right)}\left\{M\left(y_{a} B\right)^{\theta}-(b+\rho) L-r(R)-s(S)\right. \\
\\
\left.-\rho(\lambda-m(\lambda)) R-\kappa \varphi S+\beta(1-\delta) \mathbb{E} G_{a+1}\left(\sigma_{+}\right)\right\}
\end{aligned}
$$

subject to (7), (8), (10), and (11). Wage commitments in contracts $\mathcal{C}^{\tau}$ are obviously irrelevant for that problem. The same policies that solve problem (20), and in particular contracts $\mathcal{C}^{a *}$ for all $a \geq 0$, also solve problem (A1). The only difference between these two problems is that the firm is precommitted to separation rates for existing workers in the latter but not in the former problem. But since policies for the latter problem are time-consistent, both problems have the same solutions.

Third, it remains to show that these policies not only solve problem (A1) but that they also maximize the private profit value of the firm, as specified in the recursive problem (6)-(13) with the same worker search value $\rho$. Substitution of (13) shows that

$$
M\left(y_{a} B\right)^{\theta}-\kappa \varphi S=p^{r} B_{-}\left(1-\delta_{b}\right)+p^{d} q(\varphi) S
$$

Hence, the left-hand side of that term in problem (A1) can be replaced by the right-hand side together with constraint (13). Furthermore, we can write the labor costs

$$
(b+\rho) L+\rho(\lambda-m(\lambda)) R=(b+\rho) L_{0}+\left[b+\rho \frac{\lambda}{m(\lambda)}\right] m(\lambda) R,
$$

with $L_{0}=\sum_{\tau=0}^{a-1} L^{\tau+}$ denoting employment of workers in previous cohorts. Given the precommitted contracts $\mathcal{C}^{\tau *}, \tau<a$, the first term can be written

$$
\begin{aligned}
(b+\rho) L_{0} & =\sum_{\tau=0}^{a-1}\left[1-\delta_{w}^{\tau *}\left(z^{a}\right)\right] L^{\tau} \cdot(b+\rho) \\
& =\sum_{\tau=0}^{a-1}\left[1-\delta_{w}^{\tau *}\left(z^{a}\right)\right] L^{\tau}\left[w^{\tau *}\left(z^{a}\right)-\left[W\left(\mathcal{C}^{\tau *}, z^{a}\right)-U\right]+\beta(1-\delta) \mathbb{E}\left[W^{\prime}\left(\mathcal{C}^{\tau *}, z^{a+1}\right)-U\right]\right] \\
& =-\sum_{\tau=0}^{a-1} L^{\tau}\left[W^{\prime}\left(\mathcal{C}^{\tau *}, z^{a}\right)-U\right]+\sum_{\tau=0}^{a-1} L^{\tau+} w^{\tau *}\left(z^{a}\right)+\beta(1-\delta) \mathbb{E} \sum_{\tau=0}^{a-1} L^{\tau+}\left[W^{\prime}\left(\mathcal{C}^{\tau *}, z^{a+1}\right)-U\right] .
\end{aligned}
$$

For any contract $\mathcal{C}^{a}=\left(w^{a}\left(z^{k}\right), \delta_{w}^{a}\left(z^{k+1}\right)\right)_{k \geq a}$ offered to new hires $m(\lambda) R=L^{a+}$, the second term in (A2) can be written

$$
\begin{aligned}
& {\left[b+\rho \frac{\lambda}{m(\lambda)}\right] m(\lambda) R=\left[W\left(\mathcal{C}^{a}, z^{a}\right)-\beta U\right] m(\lambda) R } \\
= & w^{a}\left(z^{a}\right) L^{a+}+\beta(1-\delta) \mathbb{E}\left[W^{\prime}\left(\mathcal{C}^{a}, z^{a+1}\right)-U\right] L^{a+} .
\end{aligned}
$$

Substituting these expressions into (A1) at $\sigma=\sigma^{*}$ shows

$$
\begin{aligned}
G_{a}\left(\sigma^{*}\right)= & \max _{\left(\lambda, R, \mathcal{C}^{a}\right),\left(\varphi, S, p, p^{R}, \delta_{b}\right)}\left\{p^{r} B_{-}\left(1-\delta_{b}\right)+p^{d} q(\varphi) S-W\right. \\
(\text { A.3 }) & +\sum_{\tau=0}^{a-1} L^{\tau}\left[W^{\prime}\left(\mathcal{C}^{\tau *}, z^{a}\right)-U\right]-r(R)-s(S) \\
& \left.+\beta(1-\delta) \mathbb{E}\left\{G_{a+1}\left(\sigma_{+}^{*}\right)-\sum_{\tau=0}^{a-1} L^{\tau+}\left[W^{\prime}\left(\mathcal{C}^{\tau *}, z^{a+1}\right)-U\right]-L^{a+}\left[W^{\prime}\left(\mathcal{C}^{a}, z^{a+1}\right)-U\right]\right\}\right\},
\end{aligned}
$$


where maximization is subject to (8)-(13) with $\sigma_{+}^{*}=\left[\left(L^{\tau}, \mathcal{C}^{\tau *}\right)_{\tau=0}^{a-1},\left(L^{a+}, \mathcal{C}^{a}\right), B, z^{a+1}\right]$. In this maximization problem, the term $\sum_{\tau=0}^{a-1} L^{\tau}\left[W^{\prime}\left(\mathcal{C}^{\tau *}, z^{a}\right)-U\right]$ is predetermined and thus not subject to the maximization. Therefore, we can define the private firm value

$$
J_{a}(\sigma) \equiv G_{a}(\sigma)-\sum_{\tau=0}^{a-1} L^{\tau}\left[W^{\prime}\left(\mathcal{C}^{\tau}, z^{a}\right)-U\right]
$$

that is, the difference between the joint surplus value of firm $z^{a}$ and the surplus value of the firm's workforce at the beginning of the period. Then problem (A3) (at given state vector $\sigma^{*}$ ) is equivalent to problem (6). In particular, the firm policies $\lambda, R, \varphi, S, p^{d}$, and $p^{r}$ and $\mathcal{C}^{a *}$ that solve (A3) also solve (6). Moreover, because of $G(0,0, z)=J_{0}(0, z)$, the entry condition (21) implies the equilibrium entry condition (18). Since the resource constraint is satisfied, the solution characterized by joint-surplus maximization corresponds to a stationary competitivesearch equilibrium.

A.1.2 Resource constraint of the numeraire good. We can verify that the aggregate resource constraint for the numeraire good is satisfied in a stationary equilibrium. The budget constraint of the representative household in any period is

$\sum_{z^{a}} N\left(z^{a}\right) p^{r}\left(z^{a}\right) B\left(z^{a}\right)+e=\sum_{z^{a}} N\left(z^{a}\right)\left[\pi\left(z^{a}\right)+\sum_{\tau \leq a} L^{\tau}\left(z^{a}\right) w^{\tau}\left(z^{a}\right)\right]+b\left[\bar{L}-\sum_{z^{a}} N\left(z^{a}\right) L\left(z^{a}\right)\right]-K N_{0}$.

The left-hand side expresses the household's consumption expenditures for the different goods and for the numeraire $e$. The right-hand side gives the household's income which includes wage and profit income at all firm types $z^{a}$ plus income from unemployment minus expenditures for the entry costs of firms. Profit income of firm $z^{a}$ is

$$
\pi\left(z^{a}\right)=p^{r}\left(z^{a}\right) B\left(z^{a-1}\right)\left[1-\delta_{b}\left(z^{a}\right)\right]+p^{d}\left(z^{a}\right) q\left(\varphi\left(z^{a}\right)\right) S\left(z^{a}\right)-\sum_{\tau \leq a} L^{\tau}\left(z^{a}\right) w^{\tau}\left(z^{a}\right)-r\left(R\left(z^{a}\right)\right)-s\left(S\left(z^{a}\right)\right) .
$$

Using Equation (5) and rearranging shows that the household's consumption of the numeraire good $^{43}$ is identical to unemployment income net of the costs for recruitment, sales, firm entry, and retailers' search costs, all of which are paid in the numeraire good:

$e=b\left[\bar{L}-\sum_{z^{a}} N\left(z^{a}\right) L\left(z^{a}\right)\right]-\sum_{z^{a}} N\left(z^{a}\right)\left[r\left(R\left(z^{a}\right)\right)+s\left(S\left(z^{a}\right)\right)\right]-K N_{0}-\kappa \sum_{z^{a}} N\left(z^{a}\right) \varphi\left(z^{a}\right) S\left(z^{a}\right)$.

A.1.3 Prices and Wages. The firms' output and employment policies follow directly from the solution of the joint-surplus maximization problem (20). Hence, they are independent of our specific assumptions on price or wage commitments. Now we show how prices and wages can be calculated based on the assumptions that (i) firms offer long-term flat wage contracts and (ii) firms offer discount prices to new buyers and cannot commit to long-term price contracts. We also discuss alternatives to both arrangements.

A.1.4 Prices. Given the solutions of firm-specific buyer stocks $B$ and product market tightness $\varphi$ (all conditional on firm type $z^{a}$ ), retail and discount prices are the solutions of (13). Then, the revenue of firm $z^{a}$ is

$$
\begin{aligned}
& \operatorname{Re}\left(z^{a}\right) \equiv p^{r}\left(z^{a}\right) B\left(z^{a-1}\right)\left(1-\delta_{b}\left(z^{a}\right)\right)+p^{d}\left(z^{a}\right) q\left(\varphi\left(z^{a}\right)\right) S\left(z^{a}\right)=M\left[y_{a} B\left(z^{a}\right)\right]^{\theta}-\kappa \varphi\left(z^{a}\right) S\left(z^{a}\right) \\
& { }^{43} \text { If } e<0 \text {, we assume that the household produces }-e \text { units of the numeraire good which, together with unemploy- } \\
& \text { ment income and net of shopping costs is identical to the firms' expenditures on entry, recruitment, and sales. }
\end{aligned}
$$


The firm's (average) price is $P\left(z^{a}\right) \equiv \operatorname{Re}\left(z^{a}\right) / B\left(z^{a}\right)$ because $B\left(z^{a}\right)$ is the quantity of output units sold.

Other decentralizations without price discrimination (albeit with commitment) are also conceivable. Suppose for example that each firm charges the same price $p\left(z^{a}\right)$ for all its customers who expect that they will separate from firms with identical probability $\delta_{b}\left(z^{a}\right)$. Then optimal buyer search requires that

$$
\kappa=\frac{q\left(\varphi\left(z^{a}\right)\right)}{\varphi\left(z^{a}\right)} Q\left(z^{a}\right)
$$

where the value of a buyer matched to a firm of type $z^{a}$ satisfies the Bellman equation

$$
Q\left(z^{a}\right)=M y_{a}^{\theta} B\left(z^{a}\right)^{1-\theta}-p\left(z^{a}\right)+\beta(1-\delta) \mathbb{E}_{z^{a}}\left(\left[1-\delta_{b}\left(z^{a+1}\right)\right] Q\left(z^{a+1}\right)\right) .
$$

Given firm policies $\varphi\left(z^{a}\right)$ and $\delta_{b}\left(z^{a}\right)$, these two equations can be directly solved for nondiscriminatory prices $p\left(z^{a}\right)$ and for the firms' revenue $\operatorname{Re}\left(z^{a}\right)=p\left(z^{a}\right) B\left(z^{a}\right){ }^{44}$

A.1.5 Wages. We show how to obtain wage schedules in the competitive-search equilibrium. We distinguish between two cases: (i) All workers are paid the same wage within a firm (equal treatment); and (ii) all workers are paid flat wages over time. In both cases, as in the joint-surplus maximization problem specified in the text, separation rates for all workers in a firm are assumed to be identical: $\delta_{w}^{\tau}\left(z^{a}\right)=\delta_{w}\left(z^{a}\right)$ where $a$ is the age of the firm and $\tau$ is the worker cohort (the age of the firm when the worker was hired). Furthermore, firms are able to commit to wage contracts. ${ }^{45}$

\section{Equal treatment}

First consider an arrangement in which every firm pays the same wage to all its workers, that is, $w^{\tau}\left(z^{a}\right)=w\left(z^{a}\right)$ for all $\tau \leq a$. In this case, worker values $W$ and $W^{\prime}$ do not depend on the particular contract $\mathcal{C}^{a}$ and can therefore be written $W\left(z^{a}\right)$ and $W^{\prime}\left(z^{a}\right)$, so that (1)-(4) become

$$
\begin{aligned}
U & =\frac{m\left(\lambda\left(z^{a}\right)\right)}{\lambda\left(z^{a}\right)} W\left(z^{a}\right)+\left(1-\frac{m\left(\lambda\left(z^{a}\right)\right)}{\lambda\left(z^{a}\right)}\right)[b+\beta U], \\
W\left(z^{a}\right) & =w\left(z^{a}\right)+\beta(1-\delta) \mathbb{E}_{z^{a}} W^{\prime}\left(z^{a+1}\right)+\beta \delta U, \\
W^{\prime}\left(z^{a}\right) & =\left[1-\delta_{w}\left(z^{a}\right)\right] W\left(z^{a}\right)+\delta_{w}\left(z^{a}\right) U, \\
U & =b+\rho+\beta U .
\end{aligned}
$$

These equations can be solved for the worker surplus

$$
W\left(z^{a}\right)-U=\rho\left[\frac{\lambda\left(z^{a}\right)-m\left(\lambda\left(z^{a}\right)\right)}{m\left(\lambda\left(z^{a}\right)\right)}\right] \equiv S^{w}\left(z^{a}\right)
$$

and for wages:

$$
w\left(z^{a}\right)=b+\rho+S^{w}\left(z^{a}\right)-\beta(1-\delta) \mathbb{E}_{z^{a}}\left(\left[1-\delta_{w}\left(z^{a+1}\right)\right] S^{w}\left(z^{a+1}\right)\right) .
$$

\footnotetext{
44 The model statistics on price dynamics that we report in Table 2 change very little under this different pricing assumption. Details are available upon request.

${ }^{45}$ Rudanko (2020) considers a model in which multiworker firms apply an equal-treatment wage policy in the absence of commitment. The competitive-search equilibrium in this case is not efficient and it gives rise to endogenous wage rigidity.
} 


\section{Flat wages}

Consider now the case where every worker is paid a flat wage over time: $w_{\tau}$ is the constant wage of a worker hired in a firm at age $\tau$, and $W\left(w_{\tau}, z^{a}\right)$ denotes the worker's value in this firm at history $z^{a}$, for $a \geq \tau$. We have the Bellman equations

$$
\begin{aligned}
W\left(w_{\tau}, z^{a}\right) & =w_{\tau}+\beta(1-\delta) \mathbb{E}_{z^{a}} W^{\prime}\left(w_{\tau}, z^{a+1}\right)+\beta \delta U, \\
W^{\prime}\left(w_{\tau}, z^{a}\right) & =\left[1-\delta_{w}\left(z^{a}\right)\right] W\left(w_{\tau}, z^{a}\right)+\delta_{w}\left(z^{a}\right) U, \\
U & =b+\rho+\beta U,
\end{aligned}
$$

from which we obtain

$$
W\left(w_{\tau}, z^{a}\right)-U=w_{\tau}-b-\rho+\beta(1-\delta) \mathbb{E}_{z^{a}}\left(1-\delta_{w}\left(z^{a+1}\right)\right)\left[W\left(w_{\tau}, z^{a+1}\right)-U\right] .
$$

Hence, $W\left(w_{\tau}, z^{a}\right)-U=A\left(z^{a}\right)\left(w_{\tau}-b-\rho\right)$ where $A\left(z^{a}\right)$ satisfies

$$
A\left(z^{a}\right)=1+\beta(1-\delta) \mathbb{E}_{z^{a}}\left(1-\delta_{w}\left(z^{a+1}\right)\right) A\left(z^{a+1}\right) .
$$

To solve for wages, note that for any wage offer $w_{\tau}$ in a firm of type $z^{\tau}$,

$$
\begin{gathered}
\rho=\frac{m\left(\lambda\left(z^{\tau}\right)\right)}{\lambda\left(z^{\tau}\right)}\left[W\left(w_{\tau}, z^{\tau}\right)-b-\beta U\right]=\frac{m\left(\lambda\left(z^{\tau}\right)\right)}{\lambda\left(z^{\tau}\right)}\left[W\left(w_{\tau}, z^{\tau}\right)-U+\rho\right] \\
=\frac{m\left(\lambda\left(z^{\tau}\right)\right)}{\lambda\left(z^{\tau}\right)}\left[A\left(z^{\tau}\right)\left(w_{\tau}-b-\rho\right)+\rho\right] .
\end{gathered}
$$

This yields flat wages offered to new hires in a firm of type $z^{\tau}$ :

$$
w_{\tau}=b+\rho+\frac{\rho}{A\left(z^{\tau}\right)} \frac{\lambda\left(z^{\tau}\right)-m\left(\lambda\left(z^{\tau}\right)\right)}{m\left(\lambda\left(z^{\tau}\right)\right)} .
$$

\section{A.2 Data.}

In this appendix, we provide further details about the data.

Over the period 1995-2014 covered by the data, reporting on the number of hours changed and more than one classification standard of industries and products is used. Regarding the changes in reporting of hours worked, the first change is that all surveyed firms reported hours worked for the years up to 2006, but in subsequent years only firms with at least 50 workers reported working hours. The second change is that hours worked for white-collar workers were not included in the survey until 2002, whereas from 2003 onward hours worked by all workers are reported. We deal with the second issue by imputing working hours of blue-collar workers on the other employees.

Between 2001 and 2002, the product classification standard changes from GP 95 (Güterverzeichnis für Produktionsstatistiken 95) to GP 2002; between 2008 and 2009, the standard changes from GP 2002 to GP 2009; and between years 2011 and 2012, the standard changes from GP 2009 to GP 2009 Version12. We first harmonize the product codes for the state of Mecklenburg-Vorpommern where GP 2002 in the year 2001 was used instead of GP 95 by applying the standard GP 95. Second, we remove all products that split or merge between classifications. We keep all products with the same measurement units, for example, kilogram, meter, etc., if they neither split nor merge between standards. We exploit available conversion codes from one standard to another when harmonizing the standards. ${ }^{46}$

\footnotetext{
${ }^{46}$ See https://www.klassifikationsserver.de for these conversion codes. For the mapping of product classification GP 95 into GP 2002, the relevant document was downloaded from the Internet, which can be shared upon request.
} 
TABLE A1

ESTABLISHMENT DISTRIBUTION BY EMPLOYMENT SIZE (IN PERCENT)

\begin{tabular}{lccc}
\hline & Establishments & Employment & Revenue \\
\hline $20-49$ & 33.65 & 6.78 & 4.81 \\
$50-249$ & 53.27 & 37.78 & 34.69 \\
$250-499$ & 8.28 & 18.76 & 20.08 \\
$500+$ & 4.8 & 36.68 & 40.42 \\
\hline
\end{tabular}

Source: Research Data Centers of the Federal Statistical Office and Statistical Offices of the Länder, panel Industriebetriebe, and module Produkte, survey years 1995-2014, and own calculations.

The standards used for classifying industries are WZ 93 (Klassifikation der Wirtschaftszweige) from 1995 to 2002, WZ 2003 from 2003 to 2008, and WZ 2008 from 2009 to 2014. We convert all standards at the two-digit level to the WZ 2003 classification. The titles or descriptions of the standards WZ 93 and WZ 2003 are identical, allowing for a perfect conversion. When bringing WZ 2008 to WZ 2003, titles for four industries in WZ 2008 have no reasonable counterpart in WZ 2003. Likewise, five industries from WZ 2008 cannot be matched to WZ 2008. These industries are then left as they are. Furthermore, we pool some two industries together and as a result of cleaning some industries are dropped.

Establishments in the data produce 2.46 products on average, with about $10 \%$ producing only one product and $55 \%$ producing more than five products. Table A1 presents the distribution of establishments, employment, and revenue by size class. Over $40 \%$ (36\%) of revenue (employment) are concentrated in the largest $5 \%$ of establishments with more than 500 workers, whereas a third of establishments employ less than 50 (though 20 or more) workers.

Table A2 shows the percentage distribution of establishments, employment, and revenue across two-digit industries. Observe that there are considerable size differences, with the largest establishments in the production of motor vehicles and the smallest establishments in recycling.

\section{A.3 Extensions and Robustness.}

A.3.1 Alternative product market parameters. Here we explore the consequences of recalibrating several model parameters which are important for the customer dynamics in our model. First, in our benchmark calibration, we set $\bar{\delta}_{b}=0.43$ so that only $57 \%$ of retail customers remain with the same producer from one year to the next. Here we show what happens if we set this parameter to the much lower value $\bar{\delta}_{b}=0.1$. Second, parameter $q_{0}=2.18$ is calibrated such that a searching customer is matched with probability $1 / 2$, an arbitrary number given the lack of direct evidence on matching processes between manufacturing and retail firms. Thus we compare the consequences of setting $q_{0}$ either to $50 \%$ (1.09) or $200 \%$ (4.36) of the benchmark level. Third, we target expenditures on sales to $4 \%$ of output, instead of $2 \%$ as in the benchmark calibration.

In all these experiments, we reestimate all internally calibrated parameters. The model with lower customer separation rate requires a higher calibrated sales cost scale parameter $\left(s_{0}=\right.$ 0.0103 , about five times larger than the benchmark) to match the sales expenditure target. Likewise, the two alternative calibrations of parameter $q_{0}$ require mostly adjustments of parameter $s_{0}$ so that sales costs are roughly $2 \%$ of aggregate output, whereas all other recalibrated parameters are similar to the benchmark model. The model with $q_{0}=4.36\left(q_{0}=1.09\right)$ has a customer matching rate of $81 \%(20 \%)$. Finally, the calibration with higher sales expenditures requires a much lower value of parameter $\gamma$ (matching function elasticity). This induces firms to resort more to sales expenditures instead of discount prices in order to attract new customers.

Importantly, none of these alternative calibrations has a decisive impact on the dynamics of firm-level growth rates. This is shown in Table A3 which demonstrates that the model 


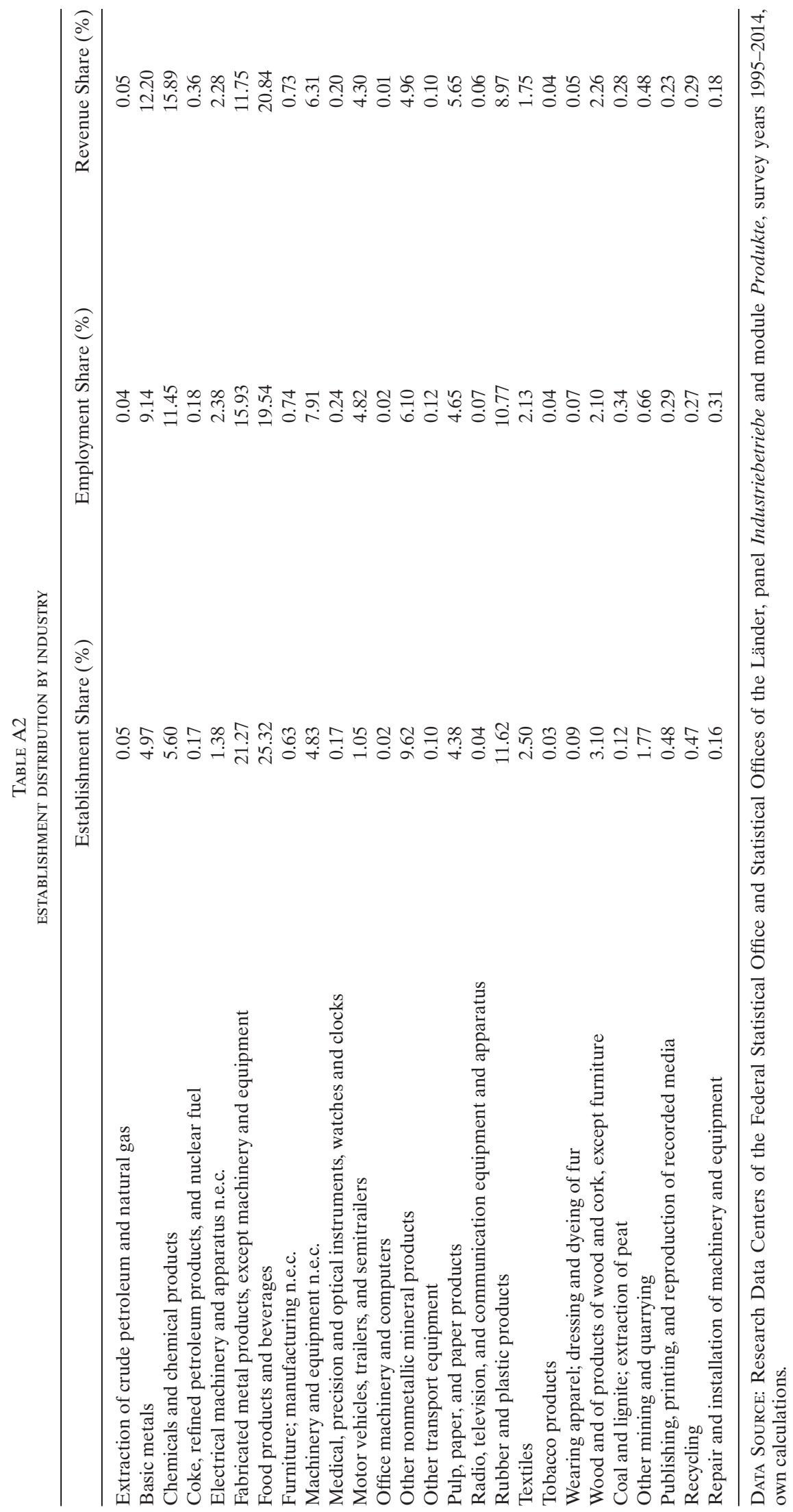


TABLE A3

THE IMPACT OF ALTERNATIVE PRODUCT MARKET PARAMETERS

\begin{tabular}{|c|c|c|c|c|c|}
\hline & Benchmark & $\bar{\delta}_{b}=10 \%$ & $q_{0}=4.36$ & $q_{0}=1.09$ & $\begin{array}{l}\text { Sales Cost } \\
4 \% \text { of Output }\end{array}$ \\
\hline$\sigma(\hat{p})$ & 0.199 & 0.197 & 0.188 & 0.201 & 0.186 \\
\hline$\sigma(\hat{q})$ & 0.334 & 0.336 & 0.336 & 0.336 & 0.336 \\
\hline$\sigma(\hat{e})$ & 0.129 & 0.127 & 0.120 & 0.126 & 0.127 \\
\hline$\sigma(\hat{y})$ & 0.393 & 0.385 & 0.392 & 0.393 & 0.383 \\
\hline$\rho(\hat{q}, \hat{e})$ & 0.298 & 0.224 & 0.326 & 0.312 & 0.206 \\
\hline$\rho(\hat{y}, \hat{e})$ & 0.583 & 0.526 & 0.585 & 0.585 & 0.512 \\
\hline$\rho(\hat{p}, \hat{q})$ & -0.536 & -0.567 & -0.524 & -0.537 & -0.567 \\
\hline$\rho(\hat{p}, \hat{e})$ & 0.064 & -0.044 & 0.024 & 0.024 & 0.118 \\
\hline$\rho(\hat{p}, \hat{y})$ & -0.436 & -0.510 & -0.442 & -0.451 & -0.458 \\
\hline $\mathrm{JC}$ rate (\%) & 3.8 & 3.1 & 3.4 & 3.5 & 3.9 \\
\hline JD rate $(\%)$ & 2.4 & 1.7 & 2.1 & 2.2 & 2.6 \\
\hline
\end{tabular}

Notes: See the notes of Table 2 for explanations.

TABLE A4

THE IMPACT OF MEASUREMENT ERROR

\begin{tabular}{|c|c|c|c|c|}
\hline & Data & Benchmark & $v=5 \%$ & $v=10 \%$ \\
\hline$\sigma(\hat{p})$ & 0.210 & 0.199 & 0.189 & 0.214 \\
\hline$\sigma(\hat{q})$ & 0.281 & 0.334 & 0.333 & 0.330 \\
\hline$\sigma(\hat{e})$ & 0.126 & 0.129 & 0.136 & 0.131 \\
\hline$\sigma(\hat{y})$ & 0.289 & 0.393 & 0.398 & 0.389 \\
\hline$\rho(\hat{q}, \hat{e})$ & -0.122 & 0.298 & 0.323 & 0.296 \\
\hline$\rho(\hat{y}, \hat{e})$ & 0.227 & 0.583 & 0.612 & 0.588 \\
\hline$\rho(\hat{p}, \hat{q})$ & -0.644 & -0.537 & -0.612 & -0.693 \\
\hline$\rho(\hat{p}, \hat{e})$ & 0.003 & 0.064 & -0.025 & -0.038 \\
\hline$\rho(\hat{p}, \hat{y})$ & -0.638 & -0.436 & -0.520 & -0.600 \\
\hline $\mathrm{JC}$ rate (\%) & 2.9 & 3.8 & 3.9 & 3.7 \\
\hline JD rate $(\%)$ & 3.0 & 2.4 & 2.5 & 2.3 \\
\hline
\end{tabular}

Notes: See the notes of Table 2 for explanations.

statistics of these alternative calibrations are rather similar to those of the benchmark model. The model with lower customer turnover $\left(\bar{\delta}_{b}=0.1\right)$ has however slightly lower rates of job creation and job destruction: firms prefer to adjust their employment a bit less if customer attrition is lower.

A.3.2 Model with measurement error. If product quantities are measured with error in our data, a spurious negative correlation between product prices (measured as sales value divided by quantity) and output quantity would arise. Importantly, it would also lead to biased estimates of the autocorrelations and standard deviations of prices and quantity labor productivity (QLP) which are key for our estimation of demand and productivity shocks. To deal with this concern, we introduce measurement error in output quantities into our model and then reestimate our model again, based on model-generated statistics of QLP and prices.

Specifically, suppose that true QLP ( $x=$ QLP, quantity per unit of labor) follows the AR(1) process

$$
\log \left(x_{i t}\right)=\rho^{x} \log \left(x_{i, t-1}\right)+\sigma^{x} \varepsilon_{i t}^{x},
$$

with standard normally distributed $\varepsilon_{i t}$, but that quantities (or labor hours) are measured with error, so that we measure in the data

$$
\log \left(x_{i t}^{D}\right)=\log \left(x_{i t}\right)+m_{i t},
$$


(a) Output

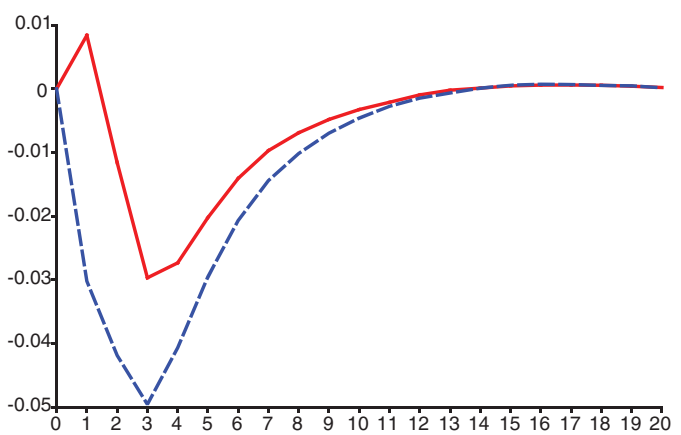

(c) Price

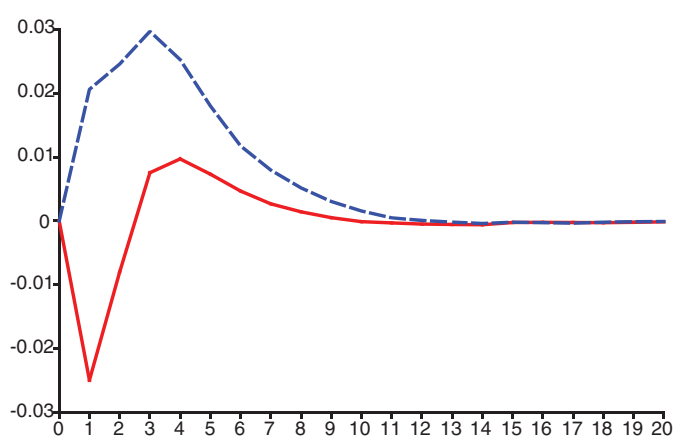

(e) Standard deviation of output growth

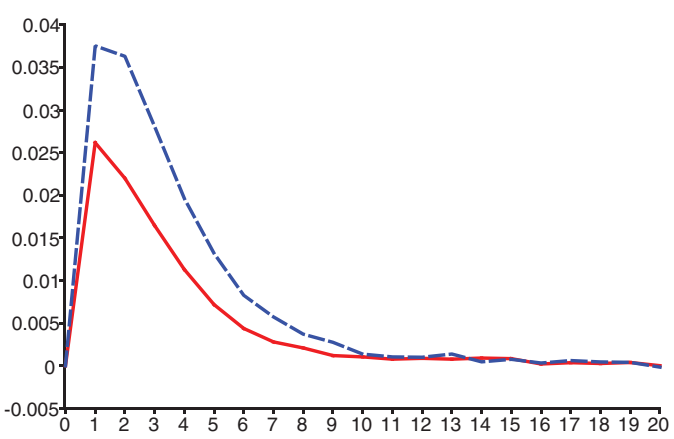

(b) Employment

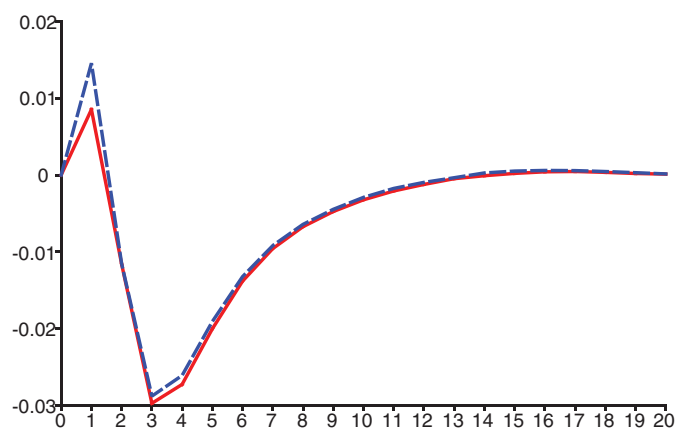

(d) Firms

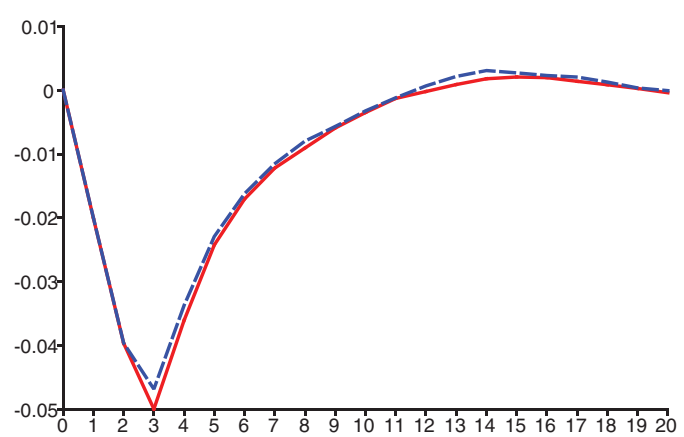

(f) Standard deviation of price growth

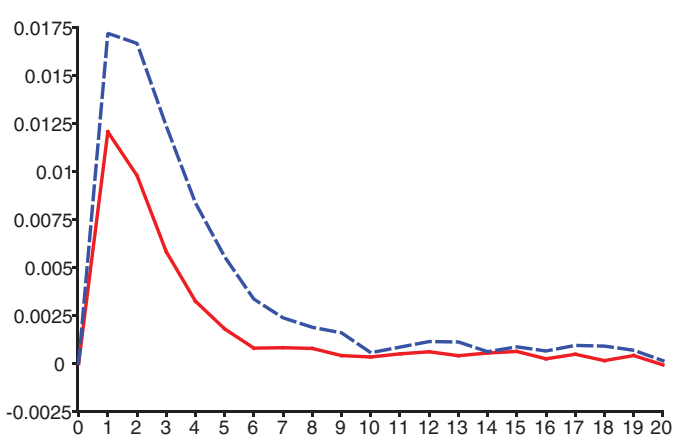

Figure A1

RESPONSES TO A 5\% DECREASE OF AGGREGATE PRODUCTIVITY (DASHED, BLUE) AND AGGREGATE DEMAND (SOLID, RED) IN THE MODEL WITH SMALL JOB SURPLUS [COLOR FIGURE CAN BE VIEWED AT WILEYONLINELIBRARY.COM]

where measurement error $m_{i t}$ is assumed to be normally distributed with mean zero and variance $v^{2}$ and independently across firms and over time. Then

$$
\begin{gathered}
\operatorname{cov}\left(\log x_{i t}^{D}, \log x_{i, t-1}^{D}\right)=\operatorname{cov}\left(\log x_{i t}, \log x_{i, t-1}\right)=\rho^{x} \frac{\left(\sigma^{x}\right)^{2}}{1-\left(\rho^{x}\right)^{2}} \\
\operatorname{var}\left(\log x_{i t}^{D}\right)=\operatorname{var}\left(\log x_{i t}\right)+v^{2}=\frac{\left(\sigma^{x}\right)^{2}}{1-\left(\rho^{x}\right)^{2}}+v^{2}
\end{gathered}
$$


These two equations allow us to back out the $\operatorname{AR}(1)$ parameters $\rho^{x}$ and $\sigma^{x}$, given our data estimates of the variance and autocorrelation of $x_{i t}^{D}$ and a given magnitude of measurement error $\nu$.

For different values of $v$, we can then proceed as follows: We recalibrate parameters $\left(\rho^{x}, \sigma^{x}\right)$ as described above and we set all directly calibrated parameters to the same values as before. All further, jointly estimated parameters, including the AR(1) parameters for demand shocks $\rho^{y}$ and $\sigma^{y}$, are reestimated based on the simulated model to which we add measurement error (of magnitude $v$ ) in quantities. Compared to the benchmark model, the recalibrated autocorrelation parameters $\rho^{x}$ and $\rho^{y}$ are larger, whereas the standard deviation parameters $\sigma^{x}$ and $\sigma^{y}$ are smaller. ${ }^{47}$ The other reestimated model parameters are rather similar.

In Table A4, we present the same statistics as shown in Table 2 when we introduce measurement error of magnitude $v=0.05$ and $v=0.1$ to those of the benchmark model. Most statistics are similar, except two of them: the negative correlations between price growth $\hat{p}$ and either productivity growth $\hat{q}$ or output growth $\hat{y}$ become more pronounced and even move closer to their data counterparts.

A.3.3 Small surplus calibration. We consider an alternative calibration of our model in which we set the flow income from unemployment (parameter $b$ ) to a much higher value so that the surplus of a job is smaller and aggregate shocks can potentially generate a larger labor market response. To this end, we set $b$ equal to $93 \%$ of the average wage and we recalibrate parameters $K$ (entry cost), $r_{0}$ (recruitment cost scale), $s_{0}$ (sales cost scale), and $m_{0}$ (matching function scale) to match the same calibration targets as in the benchmark model: firm size, sales and recruitment costs (shares of output), and the unemployment rate. Parameters governing idiosyncratic productivity and demand processes remain the same.

Figure A1 shows impulse responses to negative 5\% declines of aggregate productivity and aggregate demand parameters. In contrast to Figure 4, these first-moment shocks generate sizable declines of output and employment. Interestingly, both of these shocks also induce an increase of price and output growth dispersion, as shown in the bottom graphs of Figure A1, although they are relatively small in magnitude in comparison to the data (panel (b) of Figure 3).

\section{ACKNOWLEDGMENTS}

Open access funding enabled and organized by Projekt DEAL.

\section{REFERENCES}

Аввотт, Т. A., "Producer Price Dispersion, Real Output, and the Analysis of Production," Journal of Productivity Analysis 2 (1991), 179-95.

Acemoglu, D., and W. B. Hawkins, "Search with Multi-Worker Firms," Theoretical Economics 9 (2014), 583-628.

Albrecht, J., F. Postel-Vinay, and S. Vroman, "An Equilibrium Search Model of Synchronized Sales," International Economic Review 54 (2013), 473-93.

Argente, D., M. Lee, and S. Moreira, "The Life Cycle of Products: Evidence and Implications," Mimeo, Pennsylvania State University, 2020.

Arkolakis, C., "Market Penetration Costs and the New Consumers Margin in International Trade," Journal of Political Economy 118 (2010), 1151-99.

Arseneau, D. M., and S. K. Chugh, "Bargaining, Fairness, and Price Rigidity in a DSGE Environment," FRB International Finance Discussion Paper No. 900, Board of Governors of the Federal Reserve System, 2007.

Bachmann, R., and C. Bayer, "Investment Dispersion and the Business Cycle," American Economic Review 104 (2014), 1392-416.

Bai, Y., J.-V. Rios-Rull, and K. Storesletten, "Demand Shocks that Look Like Productivity Shocks," Mimeo, University of Rochester, 2019.

${ }^{47}$ With measurement error $\nu=0.1$, we obtain $\rho^{x}=0.688, \sigma^{x}=0.238, \rho^{y}=0.747$, and $\sigma^{y}=0.128$. 
BASU, S., and B. Bundick, "Uncertainty Shocks in a Model of Effective Demand," Econometrica 85 (2017), 937-58.

Berger, D., and J. Vavra, "Dynamics of the U.S. Price Distribution," European Economic Review 103 (2018), 60-82.

Bloom, N., "The Impact of Uncertainty Shocks," Econometrica 77 (2009), 623-85.

M. Floetotto, N. Jaimovich, I. Saporta-Eksten, and S. J. Terry, "Really Uncertain Business Cycles," Econometrica 86 (2018), 1031-65.

Burda, M. C., and J. Hunt, "What Explains the German Labor Market Miracle in the Great Recession?" Brookings Papers on Economic Activity 42 (2011), 273-319.

Carlsson, M., J. Messina, and O. N. Skans, "Firm-Level Shocks and Labour Flows," Economic Journal 131(634) (2021), 598-623.

— and O. N. Skans, "Evaluating Microfoundations for Aggregate Price Rigidities: Evidence from Matched Firm-Level Data on Product Prices and Unit Labor Cost," American Economic Review 102 (2012), 1571-95.

Chang, Y., A. Hornstein, and P.-D. Sarte, "On the Employment Effects of Productivity Shocks: The Role of Inventories, Demand Elasticity, and Sticky Prices," Journal of Monetary Economics 56 (2009), 328-43.

Christiano, L. J., M. S. Eichenbaum, and M. Trabandt, "Unemployment and Business Cycles," Econometrica 84 (2016), 1523-69.

Cooper, R., J. Haltiwanger, and J. L. Willis, "Search Frictions: Matching Aggregate and Establishment Observations," Journal of Monetary Economics 54 (2007), 56-78.

Davis, S., J. Faberman, and J. Haltiwanger, "The Flow Approach to Labor Markets: New Data Sources and Micro-Macro Links," Journal of Economic Perspectives 20 (2006), 3-26.

Den HaAn, W. J. "Inventories and the Role of Goods-Market Frictions for Business Cycles," CEPR Discussion Paper No. 9628, Centre for Economic Policy Research, 2013.

Deutsche Bundesbank, "Mark-Ups of Firms in Selected European Countries," Monthly Report, December, 2017.

Dinlersoz, E. M., and M. Yorukoglu, "Information and Industry Dynamics," American Economic Review 102 (2012), 884-913.

Elsby, M. W. L., and R. Michaels, "Marginal Jobs, Heterogeneous Firms, and Unemployment Flows," American Economic Journal: Macroeconomics 5 (2013), 1-48.

Fackler, D., C. Schnabel, and J. Wagner, "Establishment Exits in Germany: The Role of Size and Age," Small Business Economics 41 (2013), 683-700.

Foster, L., J. Haltiwanger, and C. Syverson, "Reallocation, Firm Turnover, and Efficiency: Selection on Productivity or Profitability?" American Economic Review 98 (2008), 394-425.

— - , and _ - "The Slow Growth of New Plants: Learning about Demand?" Economica 83 (2016), 91-129.

Fuchs, M., and A. Weyh, "The Determinants of Job Creation and Destruction: Plant-Level Evidence for Eastern and Western Germany," Empirica 37 (2010), 425-44.

Fujita, S., and M. NAKAJima, "Worker Flows and Job Flows: A Quantitative Investigation," Review of Economic Dynamics 22 (2016), 1-20.

Gourio, F., and L. Rudanko, "Customer Capital," Review of Economic Studies 81 (2014), 1102-36.

Hagedorn, M., and I. ManovskiI, "The Cyclical Behavior of Equilibrium Unemployment and Vacancies Revisited," American Economic Review 98 (2008), 1692-706.

Haltiwanger, J., R. S. Jarmin, and J. Miranda, "Who Creates Jobs? Small versus Large versus Young," Review of Economics and Statistics 95 (2013), 347-61.

Hopenhayn, H., "Entry, Exit, and Firm Dynamics in Long Run Equilibrium," Econometrica 60 (1992), $1127-50$.

— Journal of Political Economy 101 (1993), 915-38.

Hottman, C. J., S. J. Redding, and D. E. Weinstein, "Quantifying the Sources of Firm Heterogeneity," Quarterly Journal of Economics 131 (2016), 1291-364.

KaAs, L., and P. Kircher, "Efficient Firm Dynamics in a Frictional Labor Market," American Economic Review 105 (2015), 3030-60.

Kaplan, G., and G. Menzio, "The Morphology of Price Dispersion," International Economic Review 56 (2015), 1165-206.

_ and - "Shopping Externalities and Self-Fulfilling Unemployment Fluctuations," Journal of Political Economy 124 (2016), 771-825.

Krebs, T., and M. Scheffel, "Macroeconomic Evaluation of Labor Market Reform in Germany," IMF Economic Review 61 (2013), 664-701.

Krueger, A. B., and A. Mueller, "Job Search and Unemployment Insurance: New Evidence from Time Use Data,” Journal of Public Economics 94 (2010), 298-307. 
Leduc, S., and Z. Liu, "Uncertainty Shocks are Aggregate Demand Shocks," Journal of Monetary Economics 82 (2016), 20-35.

LuUngQvist, L., and T. J. Sargent, “The Fundamental Surplus,” American Economic Review 107 (2017), $2630-65$.

Malchin, A., and R. Voshage, "Official Firm Data for Germany," Schmollers Jahrbuch: Journal of Applied Social Science Studies 129 (2009), 501-13.

Michaillat, P., and E. Saez, “Aggregate Demand, Idle Time, and Unemployment," Quarterly Journal of Economics 130 (2015), 507-69.

Moen, E, “Competitive Search Equilibrium," Journal of Political Economy 105 (1997), 385-411.

Moscarini, G., and F. Postel-VInAY, "The Contribution of Large and Small Employers to Job Creation in Times of High and Low Unemployment," American Economic Review 102 (2012), 2509-39.

Paciello, L., A. Pozzi, and N. Trachter, "Price Dynamics with Customer Markets," International Economic Review 60 (2019), 413-46.

Perla, J., "A Model of Product Awareness and Industry Life Cycles," Mimeo, University of British Columbia, 2019.

Petrongolo, B., and C. A. Pissarides, "Looking into the Black Box: A Survey of the Matching Function," Journal of Economic Literature 39 (2001), 390-431.

Petrosky-Nadeau, N., and E. Wasmer, "Macroeconomic Dynamics in a Model of Goods, Labor, and Credit Market Frictions," Journal of Monetary Economics 72 (2015), 97-113.

$\ldots, \ldots$, and P. WeIL, "Search Demand Effects, Equilibrium Unemployment and a Wage Phillips Curve," Mimeo, Federal Reserve Bank of San Francisco, 2020.

Pozzi, A., and F. Schivardi, "Demand or Productivity: What Determines Firm Growth?" RAND Journal of Economics 47 (2016), 608-30.

Roldan, P., and S. Gilbukh, "Firm Dynamics and Pricing under Customer Capital Accumulation," Journal of Monetary Economics 118 (2021), 99-119.

Rudanko, L., "Firm Wages in a Frictional Labor Market," Mimeo, Federal Reserve Bank of Philadelphia, 2020.

SCHAAL, E, "Uncertainty and Unemployment," Econometrica 85 (2017), 1675-721.

SHI, S., "Customer Relationship and Sales," Journal of Economic Theory 166 (2016), 483-516.

Stahl, H., "Price Adjustment in German Manufacturing: Evidence from two Merged Surveys," Managerial and Decision Economics 31 (2010), 67-92. 